\title{
Fundamental frequency and regional variation in Lifou French
}

\author{
Catalina Torres, Janet Fletcher, Gillian Wigglesworth
}

May 7, 2020

\begin{abstract}
This study presents two experiments aimed at investigating tune-to-text alignment and pitch scaling in Lifou French, a variety spoken by bilingual speakers of French and Drehu. Descriptions of New Caledonian French have focused on language use of European descendants or the variety spoken in the urban region neglecting so emergent varieties spoken by the indigenous population in rural areas, like the island Lifou. Due to the reduced inventory of pitch accents, dialectal variation in French intonation has proved to be difficult to detect which has led to the assumption that French has a relatively homogeneous intonation system across varieties. This study shows that fine-grained phonetic differences in speaking tempo and at the level of tonal alignment as well as in the scaling of AP final peaks can be attributed to dialectal variation.
\end{abstract}

Index terms - Tonal alignment, Phrasing, Bilingual, French varieties, New Caledonia

\section{Introduction}

Kanaky more commonly known as New Caledonia, is sui generis $2^{2}$ a collectivity of France situated in the South Pacific about $16000 \mathrm{~km}$ away from mainland France. Lifou is a small island belonging to New Caledonia and which counts no more than 9500 inhabitants, most of them are Kanak and speakers of Drehu, an Oceanic language (Recensement général de la population 2014). From the 1950s, a mass education system was established which was aligned to the Metropolitan French syllabus (Vernaudon 2015) and although this system only fully reached Lifou during the last few decades 3 today there are almost no monolingual Drehu speakers and children are raised bilingually. New Caledonia is a linguistically diverse region with a relatively

\footnotetext{
${ }^{1}$ Term used by independentist movement and indigenous Kanak population of New Caledonia.

${ }^{2}$ After the Noumea accord from 1998 New Caledonia became "une collectivité d'outre-mer à statut particulier" hence a collectivity with a special status different to its old one as overseas territory.

${ }^{3}$ Lifou's public high school Lycée Polyvalent des Îles Williama Haudra, the only high school of all three Loyalty Islands was inaugurated in 1994 .
} 
large number of linguistic communities speaking 28 Kanak languages, additional ten migrant languages from Asia, Polynesia, Europe, and French, the lingua Franca of the region (Vernaudon 2015, Dotte et al. 2017).

Linguistic contact between languages from the Loyalty Islands and French was noted but only considered a marginal phenomenon since, at that point in time, the majority of islanders reportedly spoke their languages (Tryon 1963, Hollyman 1971). Thereafter following descriptions of New Caledonian French have focused on language use of European descendants (Hollyman 1979, Pauleau 1988). On the other side of the spectrum, studies have dealt with either French based pidgin or creole languages (Hollyman 1964, Kihm 1995), neglecting so emergent French varieties spoken by the indigenous population in rural regions, like the Loyalty Islands. Although it has been suggested there is more granularity between the opposites of Standard French and French based Creole (Ehrhart 2016) and recent acoustic studies on French in Noumea indicate there is a considerable degree of heterogeneity, at least in the representation of vowels (Lewis 2015, 2019). Arguably, New Caledonia's linguistic diversity together with an increased social mobility and greater access to the French school system (Vernaudon 2015) have led to a series of contact situations between French and local Kanak, as well as other immigrant languages. Although studies claim that some urban varieties, associated with linguistic contact situations are stigmatised (Fillol 2016, Colombel-Teuira et al. 2017), one ethnographic study on linguistic attitudes of young urban oceanic speakers suggests that these varieties of French can be the source of pride (Barnèche 2005). Taking into account the latter observations and previous studies on minoritised populations (Labov 1986, Mendoza-Denton 2014) we hypothesise that phonetic traits of French contact varieties can be carriers of covert prestige. However, only little is known on the specific phonetic characteristics, especially regarding prosodic traits of these varieties.

Prosodic studies in Lifou are of particular interest considering the rather recent but now well established contact situation between the two languages of bilinguals. French is a Romance language whose origins are found in Europe and Drehu represents an Oceanic language from the Southern Melanesian linkage (Crowley et al. 2013). Current accounts of French intonational phonology analyse it as a language with phrasal prominence marking (Jun \& Fougeron 2002), on the contrary, Drehu had been impressionistically described as having lexical stress(Lenormand 1954, Tryon 1968). However, recent acoustic investigations of the intonational phonology of Drehu indicate there is phrasal prominence marking, with a low tone demarcating the left and a high tone the right edge of the prosodic word (Torres et al. 2018b, Torres \& Fletcher 2020). Additionally, a first investigation of tonal properties of the Accentual Phrase in Lifou French claims that tonal targets in this variety are the same as those from Metropolitan French (Torres et al. 2018a). The term Metropolitan French here refers to French spoken in mainland France and encompasses speakers from Paris and Southern France, whose speech was analysed in the studies we replicate (Welby 2006, D'Imperio \& Michelas 2014). In the following, two experiments aimed at investigating, the intonational 
structure of the Accentual Phrase (AP), the intermediate phrase (ip), and the Intonation Phrase (IP) will be presented. Our aim is to firstly, describe tonal alignment in the AP, and secondly, to determine regional variation on a prosodic level.

\subsection{Intonational phonology}

A number of studies have found that intonation represents a characteristic regional marker that indicates differences between related linguistic varieties. These discrepancies can be reflected in the realisation of tonal alignment, composition of pitch accents or more complex intonation tunes. In Spanish, a language spoken in a number of countries by rather large populations, intonation has been claimed to be one of the most distinctive dialectal markers (Hualde \& Prieto 2015). Intonation contours like the Mexican declarative circumflex contour or the long fall in Argentinian Spanish (Kaisse 2001) are some examples. Similarly, in languages with smaller numbers of speakers, regionally bound differences in intonation have been attested. For example, it was found that Northern and Algherese varieties of Catalan display different pitch accent realisations compared to other varieties. Moreover, we might find differences in intonational phonology that are rooted in the diversity of intonational typology. Unlike its closely related neighbour languages Spanish and Catalan, French did not preserve the lexical stress pattern originally found in Latin. Within Autosegmental Metrical phonology (AM) it is well established that French represents a language with phrasal prominence which is marked with a pitch accent at the right edge (Jun \& Fougeron 2000, Post 2000, Jun \& Fougeron 2002, Delais-Roussarie et al. 2015). Although it is generally accepted that there are several dialectal varieties of French, compared to other Romance languages, it seems that French shows less dialectal intonational variation (Delais-Roussarie et al.|2015). It has been speculated this is due to the historically long lasting and relatively high standardization of the language, or could be as well just a side effect of a preference to study the Metropolitan variety in the school system. Alternatively, French intonational typology, which crucially differs from other Romance languages but resembles more that of languages like Bengali, Georgian, Turkish or Korean, with strong edge marking intonational events (Jun 2014, Jun \& Jiang 2018), might be the reason why regional variation has not been immediately apparent. A study on Yanbian and Seoul Korean, (Jun \& Jiang 2018) showed dialectal variation that originates in the realisation of prosodic phrasing. While the two varieties seem not to differ much in their intonational phonologies and the AP is described as the smallest prosodic unit for both Yanbian and Seoul Korean, prosodic phrasing phenomena are realised differently. Prosodic phrasing differs in its phonetic realisation and its phonological function. While the AP accounts for the dual function of marking prominence and syntactic structure in Yanbian Korean, the intermediate phrase (ip) is the prosodic unit that has the same dual function in Seoul Korean. In view of this finding, it 
can be hypothesised that French regional varieties will not differ regarding the composition of pitch accents but rather in its phonetic encoding in relation to phrasing.

\subsection{French prosody}

\subsubsection{The Accentual Phrase}

There is general agreement that in French the utterance can be divided into smaller units which have been termed differently: Intonème mineur (Rossi 1985), Intonation Group (Mertens 1987), Prosodic Word (Vaissière 1991), Rhythmic Unit (Di Cristo 1998), Phonological Phrase (Post 2000), or Accentual Phrase (Jun \& Fougeron 2000, Welby 2006), the term employed in this study.

Within AM, the Accentual Phrase (AP) represents the lowest tonally marked prosodic constituent in French (Jun \& Fougeron 2002, Welby 2006). The AP consists of one or more content words, optionally preceded by one or more function words and can contain up to seven syllables (Pasdeloup 1992).

Jun \& Fougeron (2002) proposed the notation /LHiLH*/ as the underlying tonal pattern of the canonical AP. To avoid confusion between the two low tones, we will use $/ \mathrm{L}_{1} \mathrm{HiL}_{2} \mathrm{H}^{*} /$ in this description, following a similar notation by Welby \& Lœvenbruck (2006). In French, the position of stress is fixed at the word level and its realisation relies upon the location of a word within a phrase. An obligatory phrase final rise $\left(\mathrm{L}_{2} \mathrm{H}^{*}\right)$ is associated to the metrically strongest and last full syllable of the phrase whereas the optional, non-accentual rise can occur phrase initially $\left(\mathrm{L}_{1} \mathrm{Hi}\right)$ (Jun \& Fougeron 2002, Welby 2006). As exemplified in Figure 1. tonal targets within the AP can be undershot and apart from the canonical pattern in (a), five other tonal patterns have been identified (Jun \& Fougeron 2000, Welby 2006). Moreover, for shorter AP's (of three syllables) a more common pattern is $/ \mathrm{L}_{1} \mathrm{H}^{*} /$ (Welby 2006, D'Imperio \& Michelas 2014).

As for the canonical pattern, the tone $\mathrm{Hi}$ corresponds to the optional phrase-initial prominence, and $\mathrm{H}^{*}$ represents the phrase-final prominence, which is also stronger in pitch and duration. According to Welby (2006), the initial $\mathrm{L}_{1} \mathrm{Hi}$ sequence represents an edge tone which is structurally different from the final $\mathrm{L}_{2} \mathrm{H}^{*}$ rise which is a pitch accent. The initial $\mathrm{L}_{1}$ tone is associated with the left edge of the constituent boundary of the $\mathrm{AP}$, while $\mathrm{Hi}$ is variable and not linked to any particular syllable within it. The final rise $\left(\mathrm{L}_{2} \mathrm{H}^{*}\right)$, marks the right boundary of the $\mathrm{AP}$ and has a double association, then while it marks the right edge, its peak $\mathrm{H}^{*}$ is at the same time associated with the stressed syllable. The $\mathrm{L}_{2} \mathrm{H}^{*}$ tone is considered a pitch accent because part of the tone is associated with a stressed syllable at the phrasal level. It should be noted that there is agreement on the definition of pitch accent for French as being different from that used for Germanic languages where it is associated with a lexically stressed syllable (Jun \& Fougeron 2002, Welby 2006). Additionally, the realisation of the $\mathrm{L}_{2}$ tone is more variable due to its lack of association with any 


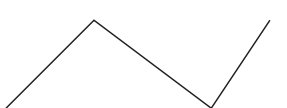

(a) $/ \mathrm{LHiLH}^{*} /$

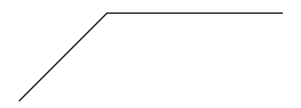

(d) $\operatorname{LHi}(\mathrm{L}) \mathrm{H}^{*}$

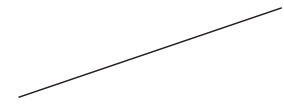

(b) $\mathrm{L}(\mathrm{HiL}) \mathrm{H}^{*}$

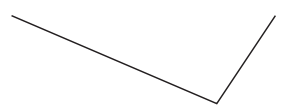

(e) (L)HiLH* (c) $\mathrm{L}(\mathrm{Hi}) \mathrm{LH}^{*}$

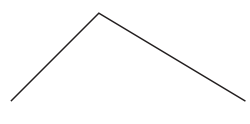

(f) LHiL* $^{*}$

Figure 1: Six predicted surface realisations of the AP from Jun \& Fougeron (2002). The notation in (a) represents the canonical pattern and the remaining five notations are alternative realisations. Undershot tones appear in parentheses.

specific syllable. The $\mathrm{L}_{2}$ tone can occur on the penultimate syllable of the AP, meaning on the syllable immediately preceding the $\mathrm{H}^{*}$, but also on the final syllable together with $\mathrm{H}^{*}$.

Although variability has been attested in tune-to-text alignment, the intonational structure of the AP seems to be very stable across varieties. A study on tonal alignment in Vaudois French ${ }^{4}$ (Sertling-Miller 2007), found that relative to the Metropolitan variety, the phonological specifications of tonal targets of the AP were not dramatically different. Interestingly, Schwab \& Avanzi (2015) report evidence for speaking rate differences with Swiss speakers from Neuchâtel and Nyon showing a slower tempo than speakers from Paris and Lyon. Is is thus conceivable that gradient variation in alignment along with durational differences could contribute to the perceived dialectal variation of intonation.

\subsubsection{The intermediate phrase (ip) and Intonation Phrase (IP)}

Current descriptions of French intonational phonology explain the Intonation Phrase (IP) is marked by a major continuation rise or a major final fall and thus by a phrase final tone ( $\mathrm{H} \%$ and $\mathrm{L} \%$ ) which can be optionally followed by a pause (Jun \& Fougeron 2000, 2002).

Although the IP represents a rather uncontroversial prosodic level, there has been an ongoing theoretical debate concerned with the existence of the intermediate phrase (ip) as further level between the AP and the IP. While Post (2000) clearly opposed an ip level, Jun \& Fougeron (2000) initially argued for it but did not maintain this view later on (Jun \& Fougeron 2002). More recent accounts examine the internal

\footnotetext{
${ }^{4}$ This variety of French is spoken in the Vaud canton in Switzerland.
} 
Figure 2: Schematic representation of intermediate phrase boundary marking through complete pitch reset in Metropolitan French. The black line represents the reference pitch level for the first phrase. The dashed line represents the reference pitch level for the second phrase. Every LH* corresponds to one AP and Hpb marks the post-boundary high tone. Adapted from D'Imperio \& Michelas (2014)

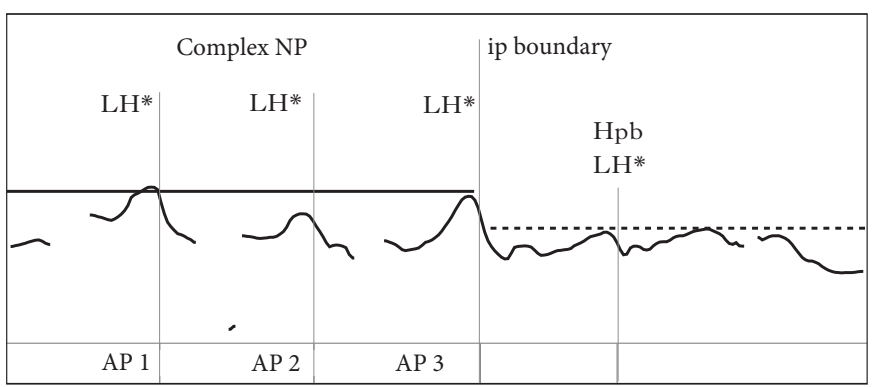

structure of the IP and find evidence for the ip level (D'Imperio \& Michelas 2010, Michelas \& D'Imperio 2012, D'Imperio \& Michelas 2014). These studies emphasise the relationship between syntactic structure and intonation and suggest the demarcation of syntactic constituents and prosodic levels can be phonetically linked. They postulate that the double association of the phrase final rise $\left(\mathrm{L}_{2} \mathrm{H}^{*}\right)$ leads to a difficulty in determining the source of variability in F0 and duration at the right edge of prosodic constituents since accentuation and phrasal boundaries always coincide in French (Michelas \& D'Imperio 2012). Conversely, a prosodic hierarchical analysis can account for these discrepancies.

D'Imperio \& Michelas (2014) find phonetic cues which under certain circumstances are stronger at the right edge of prosodic constituents and suggest there are two prosodic levels that can be distinguished, the AP and the ip. The acoustic cues associated with the right edge would be stronger at the ip than at the AP boundary. More precisely, an investigation of the right edge of subsequent AP's found that pitch-scaling effects were related to the internal structuring of the IP. Figure 2 visualises the modulation of F0 in an utterance consisting of subsequent short AP's. To investigate scaling, the height of right edge peaks was compared relative to the utterance initial peak which reportedly sets the F0 reference level within the IP. It is shown that in declarative utterances the syntactic break between a complex noun phrase (NP) and a verb phrase (VP) triggers complete pitch reset meaning that recursive downstep of subsequent AP-final LH* rises is blocked. In other words, it is found that within a larger intermediate phrase, AP final syllables are produced with lower F0 values when in non-final position (declination) but register shift and a complete reset of F0 is found when immediately preceding an ip right boundary. This means that F0 at the right boundary of the ip is scaled to the level of the IP initial peak which sets the reference level in the utterance. Additionally, they find greater vowel lengthening within ip-final syllables than in non-final ones.

An exploratory study of Lifou French finds internal restructuring within the IP which seems to be related 
Figure 3: Schematic representation of intermediate phrase boundary marking through (left) Downstep blocking in Lifou French and (right) Complete pitch reset in Metropolitan French. The black dashed line represents the reference pitch level for the first phrase and the grey dashed line represents the level of downstepped peaks. Every peak $\left(\mathrm{H}^{*}\right)$ corresponds to one AP and $\mathrm{Hpb}$ marks the post-boundary high tone.
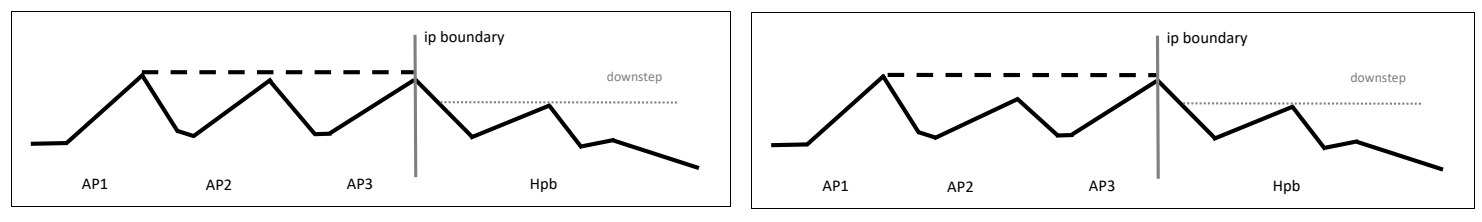

to a demarcation of the ip in this variety (Torres et al. 2019). The left panel in Figure 3 shows downstep blocking in Lifou French and the right panel complete pitch reset in Metropolitan French. Contrary to observations on the Metropolitan variety, scaling processes in Lifou French suggest there is downstep blocking across the entire ip meaning that peaks maintain the F0 level across this prosodic constituent. However, this study only included a small number of analysed utterances and it would be of interest to test whether this trend is consistent when evaluating more data from a larger number of participants. Overall these studies show gradient differences of phonetic cues marking two distinct boundaries and argue in favour of the existence of the ip as further prosodic level in Metropolitan and Lifou French. In the following, we are interested in examining whether the previously reported patterns for the ip in Lifou French can be confirmed and whether the insertion of pause after AP's conditions a higher prosodic level, namely the IP.

\section{Experiment 1}

This experiment seeks to investigate the accentual pattern of the AP, and more specifically properties of tonal alignment to segmental landmarks in Lifou French. The aim of this experiment is to describe the tonal structure of this constituent specially with regard to tune-to-text alignment and so to test whether, as stated in Torres et al. (2018a), the AP in Lifou French shares the same tonal properties as that of the Metropolitan variety. Due to the difficulty to trace dialectal differences in French intonation (Delais-Roussarie et al. 2015) which might be only small and gradient between varieties (Sertling-Miller 2007) a controlled laboratory phonological experiment appears as the most appropriate approach. This is because Lifou French has been largely undocumented and there is no literature we can draw on and more importantly because the differences are expected to be fine-grained and therefore more noticeable and measurable within controlled speech. 


\subsection{Hypotheses}

One goal of this study is to examine the properties of tonal alignment in Lifou French in comparison to Metropolitan French in order to evaluate whether intonational phonology in Lifou French shows evidence of regional variation. Therefore, the following eight hypotheses will be tested:

\section{Accent patterns}

H1 Canonical accent Pattern hypothesis : Similarly to the Metropolitan variety, it is expected that the most frequent pattern will be LHiLH* followed by LH*.

H2 Peak Height hypothesis : For LHiLH* patterns the scaling of $\mathrm{Hi}$ and $\mathrm{H}^{*}$ is different in that $\mathrm{H}^{*}$ represents the stronger peak in terms of fundamental frequency.

\section{The initial rise}

H3 EARLy L association hypothesis : The tonal alignment of the $\mathrm{L}_{1}$ tone of the initial rise is edge seeking, meaning that $\mathrm{L}_{1}$ will be situated at the edge between the monosyllabic function word and the following content word.

H4 Variant early Hi Segmental anchoring hypothesis : Tonal alignment of the early peak is variable meaning that the peak of $\mathrm{Hi}$ is dependent on time constraints and difficult to predict based on a segmental landmark in the AP.

H5 VARIANt EARly RISE CONSTANT SLOPE hypothesis : The time of the rise excursion of $\mathrm{L}_{1} \mathrm{Hi}$ is variant and it does not reliably predict the F0 excursion.

\section{The final rise}

H6 VARiant late L ASsociated tone hypothesis : Tonal alignment of the $\mathrm{L}_{2}$ tone of the final rise is variable, meaning that it is dependent on time constraints and difficult to predict based on a segmental landmark in the AP.

H7 Late H associated tone hypothesis : the position of the tone can be described with respect to the duration of the last full syllable of the AP.

H8 Variant late Rise constant Slope hypothesis : The time of the rise excursion of $\mathrm{L}_{2} \mathrm{H}^{*}$ is variant and it does not reliably predict variability in F0 excursion. 


\subsection{Methods}

\subsubsection{Participants}

Recordings were done during a field trip to Lifou in 2017 where five female speakers (age 29 - 47) participated. The participants responded to a linguistic questionnaire adapted from the Bilingual Language Profile and administered online (Gertken et al.2014). All participants reported they were permanent residents in Lifou, they acquired French and Drehu during childhood (starting at no later than 7 years with either language), they were schooled in French, and had varying degrees of school instruction in Drehu (0 to 10 years). The degree of education varied from finishing primary school for the eldest, to the equivalent of a bachelor's degree (French licence) for a 36 year old participant. Additionally, all participants work in the local community in professions that require them to speak in both languages (e.g. librarian, secretary).

\subsubsection{Materials}

Materials for this experiment were taken from Welby (2003) who investigated tonal alignment in Metropolitan French. A number of utterances was chosen because it ensured comparable data regarding the position of both rises, and eventual variation in tonal patterns. Elicitation materials consisted of a set of carrier phrases, with 17 target words consisting of $2(5 \mathrm{x}), 3(8 \mathrm{x})$ or $4(4 \mathrm{x})$ syllables. All target words had only sonorant or voiced consonants and were preceded by 1 or 2 monosyllabic function words. The position of the target phrase was manipulated and target tokens (here in bold) were inserted in sentence initial or medial positions, as illustrated in examples 1 and 3 . Appendix A contains all utterances that served as stimul ${ }^{5}$

(1) Le minimum sera calculé par Manon.

'The minimum will be calculated by Manon.'

(2) Et le minimum sera calculé par Manon.

'And the minimum will be calculated by Manon.'

(3) Le maximum, le minimum et les écart-types seront calculés par Manon.

'The maximum, the minimum, and the standard deviations will be calculated by Manon.'

(4) Le maximum et le minimum seront calculés par Manon.

'The maximum and the the minimum will be calculated by Manon.'

\footnotetext{
${ }^{5}$ The original experiment, consisted of 108 utterances, from which 48 were discarded because of reported segmental perturbations caused by voiced, non-sonorant segments, especially in the plural liaison [z]. Consequently, a set of 60 utterances was used for the analysis, which are the stimuli we employ. We did not discard two additional tokens with three and four syllables from the stimuli (see phrases 12 and 17 in Appendix A. These are tokens preceded by a plural but that start with a [h] aspiré, a word boundary which is not always realised with liaison but can be produced as sequence of vowels or with hiatus, and underlying glottalization(Boersma 2007).
} 


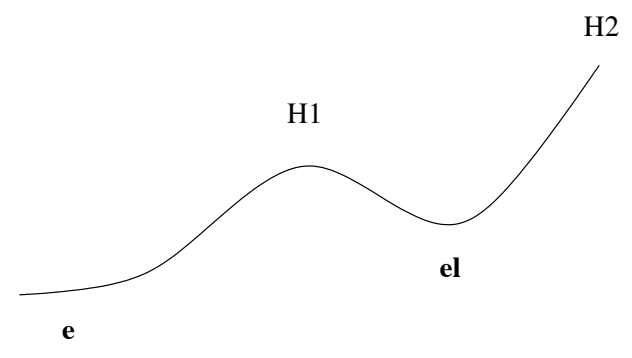

Figure 4: F0 schematization of the accentual phrase and labels used for marking the data. Taken from Welby (2003).

\subsubsection{Procedure}

The first author who is a fluent speaker of French recruited all participants, gave the necessary instructions, and conducted the experiment. The recordings were carried out in a quiet room of the local library or of the community centre in which the participants worked. Speakers were recorded in individual sessions, at a sampling rate of $48 \mathrm{kHz}$ and 16-bit depth, using a Zoom H6 Handy recorder, and a head mountedmicrophone. The materials were provided printed on paper and participants had time to read the utterances and familiarise themselves with it prior to recording.

\subsection{Data analysis}

The recorded sound files were manually transcribed and then force aligned in WebMAUS, using a grapheme to phoneme conversion, with a parameter model based on SAMPA (Kisler et al. 2017). After the forced alignment, TextGrids with three tiers were obtained, from which two were kept, one for the orthographic word and a second for phones. Subsequently, in three additional tiers, target AP's, position, and tones were identified. Tones and syllable boundaries of target tokens were marked manually. Figure 2.3 shows the points that were labelled for tones. Since automatic forced alignment is not optimised for Lifou French, manual correction was required. All utterances were visually inspected in Praat 6.0.48 (Boersma \& Weenink 2017) and the segmentation of phones in target tokens was corrected when necessary. During the correction of segmental alignment, special attention was paid to the setting of phone boundaries. A boundary was set between vowels and nasals, laterals or approximants at the point where sudden changes in both amplitude and formant structure occurred. In case the change in formant structure was gradual, the segment boundaries were marked at the midpoint of the transition from vowel to liquid or approximant. For obstruents, the start of closure was marked as the onset and the start of high amplitude periodicity was marked as the onset of the next vowel (Harrington 2010). Pauses that were inserted after the target tokens were also identified and marked. 
A hierarchical database was constructed using the EMU Speech Database Management System (Winkelmann, Harrington \& Jänsch 2017). The durational characteristics of tones and values for F0 were queried and analysed using the emuR package in R (Winkelmann, Jaensch, Cassidy \& Harrington 2017, R Core Team 2017). Due to misspellings, disfluencies within the target AP's or pitch track errors $11 \%$ of the data had to be discarded. This study reports results from 302 AP's.

The experiment included two positions for the target tokens, sentence initial (si) and sentence medial (sm). The segmental points chosen to measure the alignment of tones were determined through statistical analyses explained in 2.3.1. To investigate tonal alignment of $\mathrm{H}^{*}$, only tokens which ended on CV or CVCsonorant syllables were considered. Measurements of $\mathrm{F} 0$ were taken for the tonal targets $\mathrm{L}_{1}$ and Hi of the initial rise, as well as the low tone in the late rise $\mathrm{L}_{2}$ and the tonal target $\mathrm{H}^{*}$. To further examine the two rises, following Welby \& Lœvenbruck (2006), pitch excursion was measured as the difference of F0 in $\mathrm{Hz}$ between the $\mathrm{L}$ and the following $\mathrm{H}$ tone. Rise time was calculated as the time difference between the two tones of the (i) initial $\mathrm{L}_{1} \mathrm{Hi}$ and (ii) final rise $\mathrm{L}_{2} \mathrm{H}^{*}$. The slope was calculated with the formula $\mathrm{m}=\mathrm{y}^{b}-\mathrm{y}^{a}$ $/ \mathrm{x}^{b}-\mathrm{x}^{a}$, where $\mathrm{y}^{a}$ is the $\mathrm{F} 0$ value of $\mathrm{L}_{1}, \mathrm{y}^{b}$ is the $\mathrm{F} 0$ value of $\mathrm{Hi}, \mathrm{x}^{a}$ is the time of $\mathrm{L}_{2}$, and $\mathrm{x}^{b}$ is the time of the $H^{*}$, from Welby (2006), also employed by Fougeron \& Jun (1998) under the term "average velocity". In other words, this formula divides the F0 excursion size of a rise by its rise time.

\subsubsection{Statistical analyses}

The Wilcoxon Signed-Rank test was used to determine whether the F0 peaks of Hi and $\mathrm{H}^{*}$ are significantly different in the LHiLH* pattern. This method is a non-parametric statistical hypothesis test with which matched data from repeated observations of the same subject can be analysed. This means that it can be decided whether the corresponding data distributions are identical without assuming them to follow a normal distribution. To examine which variables were the most reliable predictors of the alignment of tonal targets $\left(\mathrm{L}_{1}, \mathrm{Hi}, \mathrm{L}_{2}\right.$, and $\left.\mathrm{H}^{*}\right)$, stepwise regression analyses were performed, together with a cross-validation technique, similar to Welby (2006). We used $80 \%$ of the data as training data. The first step consisted in establishing the dependent variable which would account for most of the variance in the data, then the contribution of individual variables was tested. This method allows to determine whether adding more independent variables significantly improves a model. Predictor variables were either continuous or binary, in the latter case, a dummy variable with two levels was coded (e.g., one and two, or yes and no). Only independent variables that were found to be statistically significant were retained in the model. To determine how accurately the model predicts the response we used the RMSE (root mean square error) and SI (scatter index) as measures of goodness of fit. The SI is a normalised value which is calculated by dividing the RMSE by the mean of the measured data. An SI value lower than one means the estimations are acceptable. To examine how much 


$\begin{array}{lll}\text { Pattern } & \text { Metropolitan } & \text { Lifou } \\ \mathrm{L}_{1} \mathrm{HiL}_{2} \mathrm{H}^{*} & 50 \% & 59,3 \% \\ \mathrm{~L}_{1} \mathrm{H}^{*} & 21 \% & 23 \% \\ \mathrm{~L}_{1} \mathrm{~L}_{2} \mathrm{H}^{*} & 18 \% & 8 \% \\ \mathrm{~L}_{1} \mathrm{HiH}^{*} & 4,5 \% & 7,3 \% \\ \mathrm{~L}_{1} \mathrm{Hi} & 4 \% & 1,3 \% \\ \mathrm{~L}_{1} \mathrm{HiL}^{*} & - & 1 \% \\ \mathrm{~L}_{2} \mathrm{Hi} & 2 & -\%\end{array}$

Table 1: Realisation of tonal patterns in Metropolitan French (Welby 2003) and Lifou French.

of the variability in F0 excursion size is predicted by rise time and investigate the slope, regression analyses and Pearson's correlation tests were performed. $P$-values $<0.05$ are considered significant. The software R (R Core Team 2017) and the statistics package lme4 (Bates et al. 2015) were used to carry out all statistical analyses.

\subsection{Results}

\subsubsection{Accent patterns}

Table 1 shows a summary with the percentage of tonal patterns found in Lifou French and Metropolitan French (Welby 2003). These results are evidence in favour of the CANONICAL ACCENT PATTERN HYPOTHESIS which predicted that $\mathrm{LHiLH}^{*}$ would be the most frequent pattern found, followed by $\mathrm{L}_{1} \mathrm{H}^{*}$ as second most frequent. One possible reason for the higher percentage of LHiLH* patterns in the Lifou data could be the additionally inserted tokens with three and four syllables which was not part of the study by Welby (2003) and led to eight more possible AP's with four to six syllables. Measurements taken for the early and late peaks show that $\mathrm{Hi}$ is lower (mean $226 \mathrm{~Hz}$ ) than $\mathrm{H}^{*}$ (mean $245 \mathrm{~Hz}$ ). The Wilcoxon Signed-Rank test reveals this difference is significant $(\mathrm{V}=4526, \mathrm{p}<.0001)$. This result supports the PEAK Height hypothesis which predicted peak values for $\mathrm{Hi}$ and $\mathrm{H}^{*}$ would be similar to those in the Metropolitan variety.

\subsubsection{The initial rise}

A detailed inspection of tonal alignment of the initial and final rise shows that more similarities are found. In our corpus, all AP's were realised with an $\mathrm{L}_{1}$ tone which straddled the function word and content word boundary. All of these tone were included in the following analyses $(\mathrm{N}=302)$. Figure 5 shows the alignment of the initial low is mostly situated at the boundary between function and content word, note that there are almost no differences in the median values between the two positions in the experiment. Two models tested whether the alignment of $\mathrm{L}_{1}$ was better described with respect to the left-edge of the AP or the left-edge of the function word immediately preceding the content word. Model A had LATENCY OF $\mathrm{L}_{1}$ FROM 


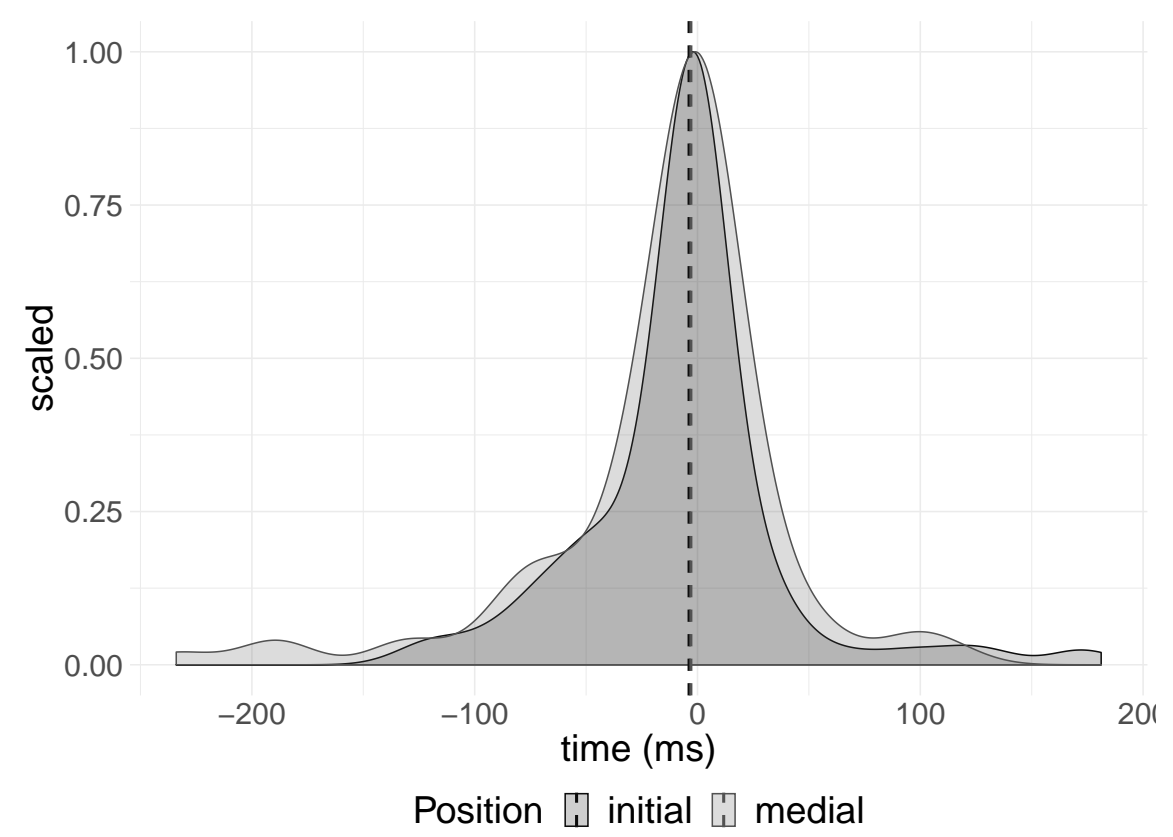

Figure 5: Density plot of the early $\mathrm{L}_{1}$ tone in all patterns $\left(\mathrm{L}_{1} \mathrm{HiLH}^{*}, \mathrm{~L}_{1} \mathrm{H}^{*}, \mathrm{~L}_{1} \mathrm{LH}^{*}, \mathrm{~L}_{1} \mathrm{Hi}, \mathrm{L}_{1} \mathrm{HiL}^{*}\right)$, dotted lines indicates the median according to position. A positive value in ms indicates the tone was realised after the function word and content word boundary. Realisation at $0 \mathrm{~ms}$ indicates that the tone was realised precisely at the boundary between the function word and the content word.

LEFT-EDGE OF AP as dependent variable and DURATion AP as independent variable. The adjusted $\mathrm{R}^{2}$ was of 0.28 meaning that the model accounted for $28 \%$ of the variance in the data. Model B had LATENCY FROM LEFT-EDGE OF LAST FUNCTION WORD as dependent variable and DURATION OF LAST FUNCTION WORD as independent variable and FUNCTION WORD (one, two) as further variable. The adjusted $\mathrm{R}^{2}$ value of this model was of 0.48 meaning that it accounts for $48 \%$ of the variance in the data of which $47 \%$ can be attributed to the duration of the last function word. The independent variable function word did not reach statistical significance $(p=.1)$ and was therefore not retained in the model. The test data validated the model with an SI value of 0.24 . Table 3 summarises the coefficient values obtained for independent variables in the selected models as well as the RMSE and SI values that validate the same models. Results for $\mathrm{L}_{1}$ are in favour of the EARLY L ASSOCIATION HYPOTHESIS which predicts that the $\mathrm{L}_{1}$ tone is associated to the edge between the last function word and the first content word syllable of the AP.

A fourth hypothesis predicts that the early peak in $\mathrm{L}_{1} \mathrm{Hi}$ is variant, therefore not anchored to a particular syllable and that it can not be reliably predicted based on a segmental landmark. Figure 6 shows the alignment of $\mathrm{Hi}$, in patterns $\mathrm{LHiLH}^{*}, \mathrm{LHiH}^{*}, \mathrm{LHi}$, and $\mathrm{LHiL}^{*}$, moves between syllables, with it falling $54 \%$ on the first and $46 \%$ on the second syllable of content words $(\mathrm{N}=209)$. Three models $(\mathrm{C}, \mathrm{D}, \mathrm{E})$ with two different dependent variables were used to determine whether the tone seeks to align with respect to the left- 
edge of the word initial syllable or of the AP. Two models (C, D) used LATENCY of Hi From LEFT-EDGE OF WORD INITIAL SYLLABLE as the dependent variable. Model C used DURATiOn of CONTENT Word INITIAL SYLLABLE as independent variable. The adjusted $\mathrm{R}^{2}$ of model $\mathrm{C}$ was of 0.25 indicating that it only explained $25 \%$ of the data. Model D used DURATION OF CONTEnT WORD as independent variable and provided a more reliable but still not satisfactory result with an adjusted $\mathrm{R}^{2}$ value of 0.33 showing that it accounts for $33 \%$ of the variance in the data. Since the peak in Hi does not seem to be anchored to a fixed distance from the onset of the content word, we proceed to examine whether the AP is a better predictor. Model C used the LATENCY OF Hi FROM LEFT-EDGE OF AP as dependent variable, together with DURATION OF AP and FUNCTION WORD (one, two) and the dummy variable TRISYLLABle (yes, no) as independent variables. For model $\mathrm{E}$ the adjusted $\mathrm{R}^{2}$ accounted for $53 \%$ of the data, of which $43 \%$ can be attributed to the duration of the AP. The independent variables function word $(p<.0001)$ and the dummy variable trisyllable $(p=.02)$ were statistically significant and therefore retained. Other dummy variables did not improve the model. The test data validated model $\mathrm{E}$ with an SI value of 0.19. This indicates that the position of Hi is more likely to depend on the duration of the AP in ms than on a fixed segmental landmark. Additionally, the results indicate that the number of syllables in the AP also has an influence with an alignment of Hi occurring approx. $58 \mathrm{~ms}$ later when two function words precede the content word. Considering that the Hi peak is realised on the first and second syllables, and that the duration of the AP is the best predictor of its placement, it seems plausible to conclude that VARIANT EARLY Hi SEGMENTAL ANCHORING HYPOTHESIS is applicable.

An investigation of the slope in initial rises was conducted to examine whether this factor appears to be variant, as predicted in H5. Table 2 shows the mean slopes and standard deviation for speakers of Lifou and Metropolitan French (Welby 2006). To assess whether speakers seek to achieve a constant slope a regression analysis was performed. The aim was to establish how much of the variability in F0 excursion size could be predicted by rise time. In case the slope is constant, longer rise times should be correlated with larger F0 excursions. Results show that rise time did not predict the F0 excursion reliably since the regression analysis only accounted for $10 \%$ of the variance. Additionally, only a low correlation of $(r=0.33$, $\mathrm{df}=196)$ between F0 excursion and rise time could be established. Regarding the rise time of $\mathrm{L}_{1} \mathrm{Hi}$, Welby (2006) reports a fair amount of variation reaching from under 50 to nearly $300 \mathrm{~ms}$. Also in Lifou we can establish variation ranging from 70 to up to $391 \mathrm{~ms}$ which indicates that the rise time in Lifou French is slower. The data appears in favour of the VARIANT EARLY RISE CONSTANT SLOPE HYPOTHESIS. 


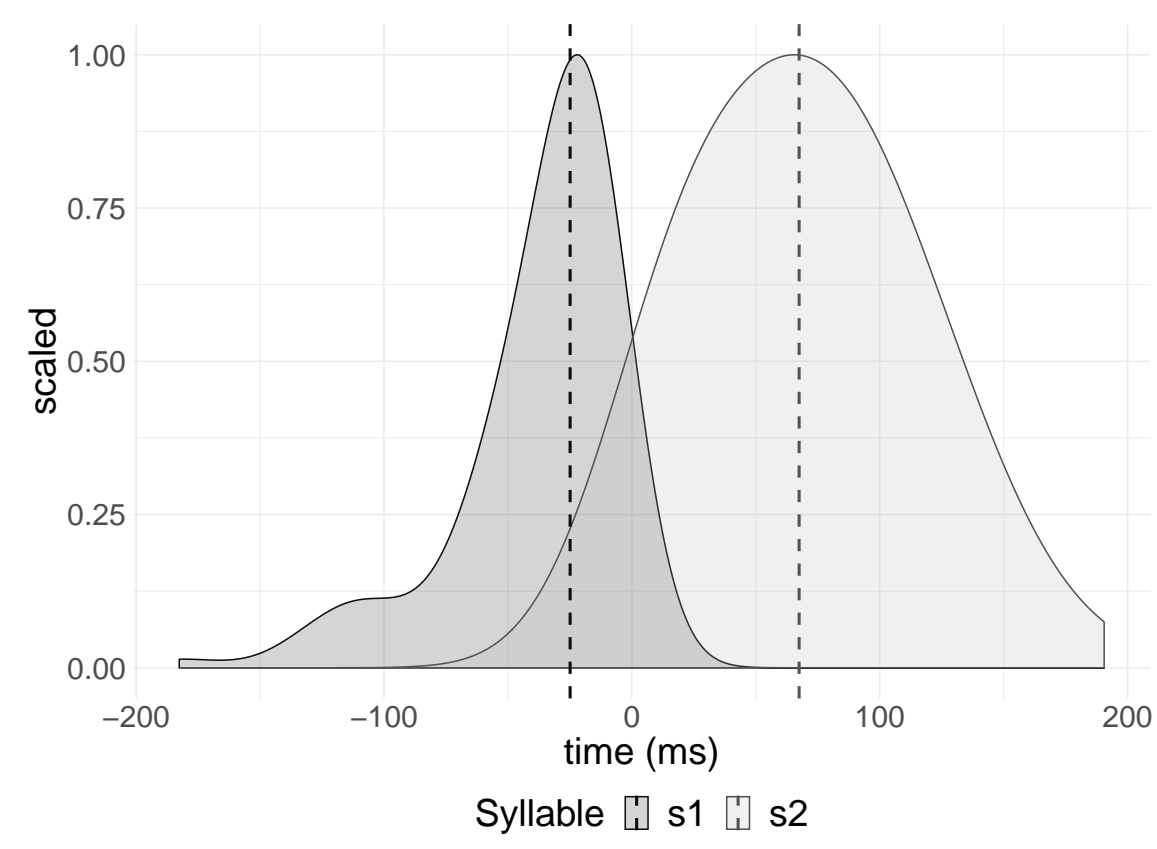

Figure 6: Density plot of the early Hi tone from the LHiLH*, LHiH*, and LHiL* patterns, dotted lines indicate the median. A positive value in ms indicates the tone was realised after the first and second syllable boundary of the content word. Realisation at $0 \mathrm{~ms}$ indicates that the tone was realised precisely at the boundary between the two syllables.

\subsubsection{The final rise}

In $\mathrm{H} 6$ the prediction is that the tonal alignment of $\mathrm{L}_{2}$ is variant and the tone is not anchored to any specific segmental landmark. $\mathrm{L}_{2}$ tones found in the patterns $\mathrm{LHiL}_{2} \mathrm{H}^{*}$ and $\mathrm{LL}_{2} \mathrm{H}^{*}$ are included in the following analyses $(\mathrm{N}=204)$. As shown in Figure 7 , the tone is mostly realised in a time frame close to the left edge of the final syllable. It should be noted that the alignment of the $\mathrm{L}_{2}$ tone is not only in the final (74\%) but also in a preceding syllable (26\%). Welby (2006) did not find a reliable measure for the alignment of $\mathrm{L}_{2}$ and states that for some speakers in her study, the latency from the left edge, for others, the latency from right edge of the AP final syllable was a better measure. The models F, G, and $\mathrm{H}$ used three different dependent variables and sought to determine which is the best segmental landmark to predict the alignment of $\mathrm{L}_{2}$. Model $\mathrm{F}$ used LATENCY OF $\mathrm{L}_{2}$ FROM RIGHT EDGE OF FINAL SYLLABLE as dependent variable and DURATION FINAL SYLLABLE as independent variable. The adjusted $\mathrm{R}^{2}$ shows that the model only accounts for $32 \%$ of the data. Model $\mathrm{G}$ used Latency of $\mathrm{L}_{2}$ FROM Left EdGe of the FinAl Syllable as dependent variable and DURATION FINAL SYLLABLE as independent variable. This model accounts for $24 \%$ of variance in the data. Model H used LATENCY OF $\mathrm{L}_{2}$ FROM RIGHT EDGE OF THE WORD INITIAL SYLLABLE as dependent variable and CONTENT WORD DURATION as independent variable plus the two dummy variables DISYLLABLE (yes, no) and TRISYLLABLE (yes, no), to account for number of syllables in the word. The adjusted $\mathrm{R}^{2}$ shows that this 


\begin{tabular}{ccccc}
\hline \multicolumn{3}{c}{ Initial rise } & \multicolumn{2}{c}{ Final rise } \\
\hline Speaker & Lifou & Metropolitan & Lifou & Metropolitan \\
\hline 1 & $.38(.16)$ & $.24(.09)$ & $.28(.12)$ & $.37(.12)$ \\
2 & $.25(.11)$ & $.33(12)$ & $.24(.19)$ & $.26(.10)$ \\
3 & $.18(.07)$ & $.27(.10)$ & $.23(.10)$ & $.31(.08)$ \\
4 & $.34(.11)$ & $.27(.11)$ & $.31(.15)$ & $.22(.07)$ \\
5 & $.31(.24)$ & $.34(.16)$ & $.26(.13)$ & $.44(.13)$ \\
6 & - & $.27(.09)$ & - & $.28(.13)$ \\
7 & - & $.32(.14)$ & - & $.24(.09)$ \\
\hline
\end{tabular}

Table 2: Mean slopes for the early and late rise in Lifou and Metropolitan French (Welby 2006). Standard deviations are given in parentheses.

\begin{tabular}{llllcccc}
\hline Model & Intercept & Coefficient 1 & Coefficient 2 & Coefficient 3 & Adj. R $^{\mathbf{2}}$ & RMSE & SI \\
\hline B & 24.5 & 0.75 (dur. last fw) & & & 0.48 & 30.66 & 0.24 \\
E & 81.5 & 0.33 (dur. AP) & 57.58 (two fws) & -25.44 (trisyllable) & 0.53 & 73.39 & 0.18 \\
H & 79.96 & 0.32 (dur. token) & -179.35 (disyllable) & -92.74 (trisyllable) & 0.68 & 74.19 & 0.3 \\
K & -53.05 & 0.93 (dur. last syl) & 20.34 (pause, yes) & -16.07 (rise, only) & 0.75 & 39.28 & 0.17 \\
\hline
\end{tabular}

Table 3: Coefficients of selected models obtained using the training data and values for goodness of fit (RMSE and SI) obtained using the test data.

model accounts for $68 \%$ of the variance of which $49 \%$ can be attributed to the duration of the content word. The predictor variables disyllable $(p<.0001)$ and trisyllable $(p<.0001)$ were statistically highly significant. The test data validated model $\mathrm{H}$ with an SI value of 0.3 . Since the dummy variable TETRASYLLABLE did not improve the model we find that the realisation of the $\mathrm{L}_{2}$ in short content words (disyllables and trisyllables) depends on the duration of the word whereas it is highly frequent in words with four or more syllables. This result supports the VARIANT LATE L ASSOCIATED TONE HYPOTHESIS.

The timing of the peak of the late rise is compared for the patterns $\mathrm{LHiLH}^{*}, \mathrm{LLH}^{*}$, and $\mathrm{LH}^{*}(\mathrm{~N}=260)$. Figure 8 shows the $\mathrm{H}^{*}$ peak is affected by whether or not there are tones other than $\mathrm{L}_{1}$ in the AP, with it being realised earlier in the syllable when only $\mathrm{L}_{1}$ precedes $\mathrm{H}^{*}$. It also shows that the insertion of a pause causes the peak to be realised earlier. Two models $(\mathrm{J}, \mathrm{K})$ investigated the alignment of $\mathrm{H}^{*}$. Model J had LATENCY OF H* FROM RIGHT EDGE OF FINAL SYLLABlE as dependent variable and DURATION OF FINAL SYLLABLE as independent variable. The adjusted $\mathrm{R}^{2}$ of this model was of only 0.002 meaning that it accounted for less than $1 \%$ of the variance. Model $\mathrm{K}$ had LATENCY OF $\mathrm{H}^{*}$ FROM LEFT EDGE OF FINAL SYLLABLE as dependent variable and DURATION OF FINAL SYLLABle together with PAUSE (yes, no) and RISE (only, final) as independent variables. The dummy variable rise was created putting together rises from $\mathrm{LHiL}_{2} \mathrm{H}^{*}, \mathrm{LL}_{2} \mathrm{H}^{*}$ into the category final, and rises in $\mathrm{L}_{1} \mathrm{H}^{*}$ into only. The adjusted $\mathrm{R}^{2}$ shows that the model explains $75 \%$ of the variance of which $70 \%$ can be attributed to the duration of the final syllable. Since the independent variables pause $(p=.009)$ and rise $(p=.05)$ reached statistical significance, they were kept 


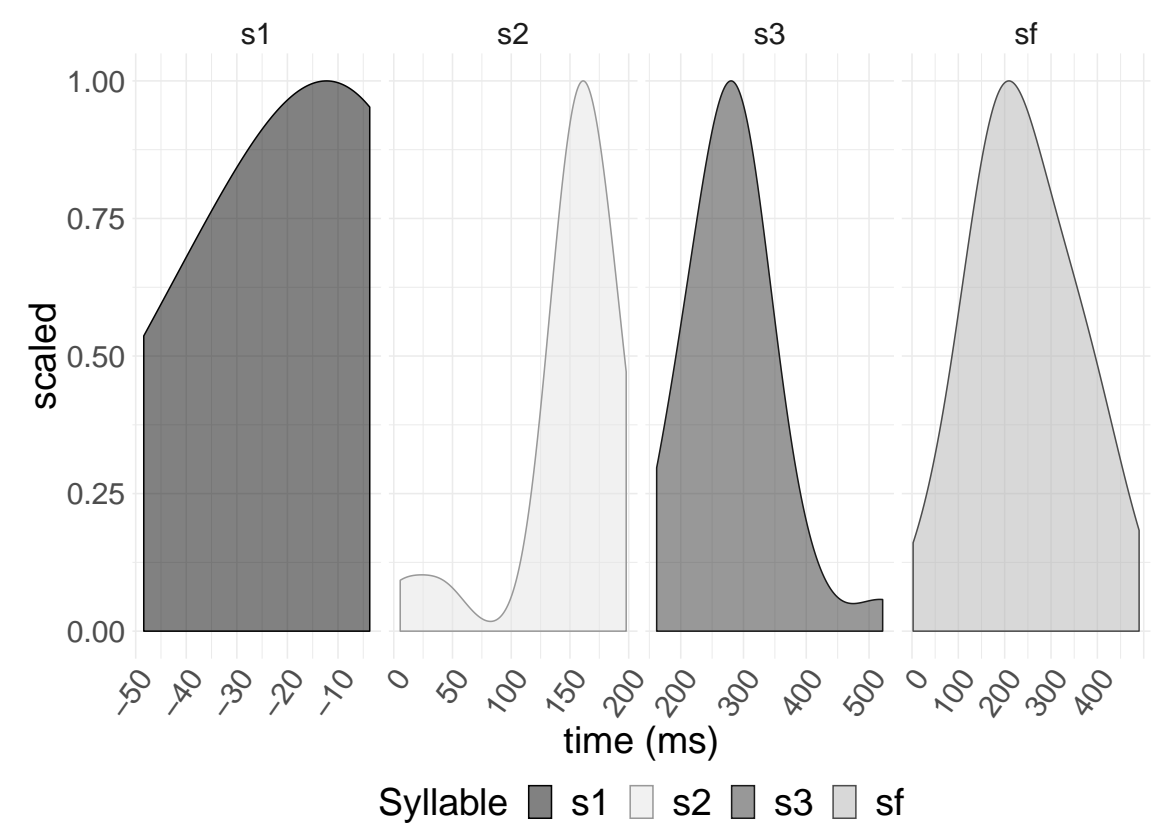

Figure 7: Density plots of the latency of late $\mathrm{L}_{2}$ tone from the $\mathrm{LHiL}_{2} \mathrm{H}^{*}$ and $\mathrm{LL}_{2} \mathrm{H}^{*}$ patterns. A positive value in $\mathrm{ms}$ indicates the tone was realised past the right edge of the initial syllable of the content word. Realisation at $0 \mathrm{~ms}$ indicates that the tone was realised precisely at the boundary between the first and second syllables.

in the model which was validated with an SI value of 0.17 in the test data. Results reveal that the peak was realised earlier when no pause followed after the token. For the LH* pattern, the peak was realised, in average, at $181 \mathrm{~ms}$ from the left edge of the final syllable, when no pause followed and at $281 \mathrm{~ms}$ in pre-pausal items. In contrast to the Metropolitan experiment, in the present data there are no cases of peaks being realised past the offset of the last syllable of the AP. Although this only represented a very small proportion in the Metropolitan data (3\%). These results suggest the LATE H ASSOCIATED TONE HYPOTHESIS can be confirmed and that the final peak is aligned to the final syllable. For H8, the slope was calculated to investigate whether it is constant and whether the F0 excursion can be predicted by the rise time. Mean values and standard deviations are in Table 2, The timing of the rise shows here too variation that ranges from 77 to $697 \mathrm{~ms}$. A regression analysis between F0 excursion and rise time shows that the model only accounts for $23 \%$ of the variance. The correlation test between the same variables shows a correlation of 0.48 which is moderate and higher than that of the initial rise. The VARIANT LATE RISE CONSTANT SLOPE HYPOTHESIS is palpable, however, it seems the final rise is less variable than the initial rise. 

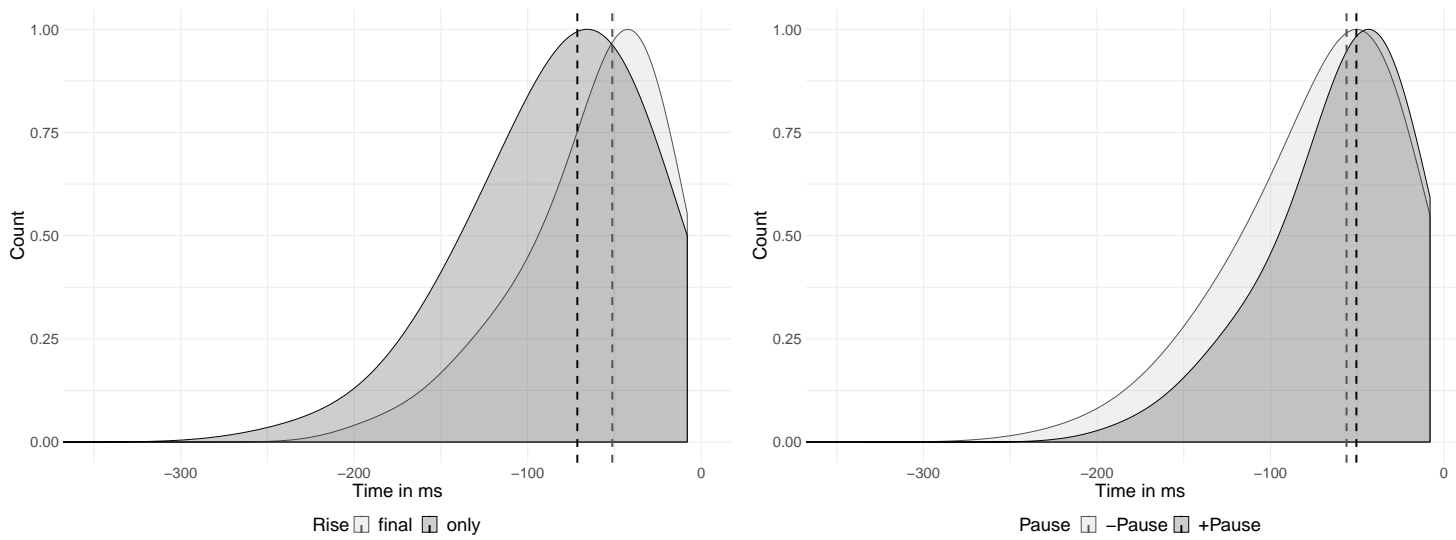

Figure 8: Density plots of the late $\mathrm{H}^{*}$ tone. The left panel shows contrast between tokens with a final rise (LHiLH* and $\mathrm{LH}^{*}$ ) and only one rise $\left(\mathrm{LH}^{*}\right)$. The right panel shows $\mathrm{H}^{*}$ realised prior to a pause (+Pause) and with no following pause (-Pause), dotted lines indicate the median. A negative value in ms indicates the tone was realised before the right boundary of the content word. Realisation at $0 \mathrm{~ms}$ indicates that the tone was realised precisely at the end of the final syllable.

\subsubsection{Speaking rate}

Since differences in rise time could be established it is conceivable that participants in Lifou might display a slower speaking rate than in the study by Welby (2006). Speaking rate was calculated by taking the duration of target AP's in ms and dividing it by the number of phones uttered. The mean phone duration was used to arrive at an approximate number of phones uttered per second. We could establish that speakers in Lifou produced in average 10.3 to 12.5 phones/second which is less phones than speakers in the Metropolitan study produced per second at normal speech rate (11.5 to 14.2). This suggests speaking rate is slower in Lifou French.

\subsection{Summary}

This first experiment sought to provide a more detailed investigation of the intonational phonology of Lifou French. It was the aim to test whether as suggested by Torres et al. (2018a), the AP shares the same tonal properties as those reported for the Metropolitan variety. Results indicate that the same tonal targets are found in both varieties and that these show comparable tune-to-text alignment. It was established that in Lifou French the initial $\mathrm{L}_{1}$ tone is edge seeking and occurred close to the boundary between the function word and the following content word. Meanwhile the $\mathrm{Hi}\left(\right.$ of $\mathrm{L}_{1} \mathrm{Hi}$ ) represents a variant tone which is most reliably predicted by the duration of the AP and which can be associated to the the first or second syllables of the content word of the AP. Neither for the initial nor for the final rise the rise time was a reliable predictor of the excursion size which in turn is in agreement with previous observations in the Metropolitan variety. 
However, our data suggests that the rise time is slower in Lifou French which could contribute to a perceived difference between the two varieties and be an indicator of regional variation. Further inspection of speaking rate suggests that Lifou French speakers produce in average less phones per second which is in line with the slower rise time. One interesting, although perhaps marginal observation, is that no $\mathrm{H}^{*}$ tone was realised past the offset of the final syllable and that the insertion of a pause coincided with a later placement of the peak. Finally, the majority of $\mathrm{L}_{2}$ tones (namely $74 \%$ ) were found in the final syllable which suggests a preference for a realisation of $\mathrm{LH}^{*}$ within the last syllable of the AP. We could establish that the duration of the content word and number of syllables (two-three syllables) were the best predictors for the realisation of $\mathrm{L}_{2}$. These results suggest tonal targets in French are stable across varieties and fine differences in their implementation such as rise time and speaking rate are likely to have an influence on perceived rhythmic differences.

\section{Experiment 2}

Experiment 1 showed that the tonal realisation in Lifou French is very close to that of Metropolitan French and allows us to predict that short AP's will be produced with a $\mathrm{H}^{*}$ peak at the right edge. In Experiment 2 we are interested in evaluating whether or not the intermediate phrase constitutes a further level in the prosodic hierarchy in Lifou French. Recent investigations of Metropolitan speakers in southern France find evidence for the an ip level (D'Imperio \& Michelas 2014, Michelas \& D'Imperio 2012). It is argued that differences at the right boundary of constituents which are related to a rescaling of F0 and pre-boundary lengthening are involved in the demarcation of the ip in contrast to the AP. Similarly, an exploratory study on Lifou French finds evidence for internal restructuring of scaling processes within the IP (Torres et al. 2019). Experiment 2 seeks to investigate whether further evidence in favour of the ip is found in Lifou French and if so to determine which is the role of F0 in demarcating the right boundary at this level. We predict that in case there is a further prosodic level between the AP and the IP, the right boundary of the ip should be phonetically distinguishable from boundaries at a lower and a higher level. Since speech rate can constrain prosodic phrasing, leading for example to modifications in the shape of F0 or a lowering of peaks (Fougeron \& Jun 1998), we additionally tested the effect of speech rate on tonal scaling relative to the existence of an ip in French. This allows us to identify how robust the insertion of an ip boundary is across rates. Experiment 2 was realised in two phases during two separate field work trips in Lifou carried out in 2018. In both cases the experiment aimed at investigating phrasing in Lifou French and the structure of the experiment and materials remains the same, while the stimuli presented to the participants were different in both sessions. All phrases used as stimuli during the first and the second elicitation are listed in Appendix 


\subsection{Hypotheses}

Based on findings from Experiment 1 it can be predicted that AP's, like the ones used in this experiment, will be produced with the patterns previously discussed, e.g., $\mathrm{L}_{1}\left(\mathrm{HiL}_{2}\right) \mathrm{H}^{*}$. Since we are interested in scaling processes our analyses will focus on the peak height of the $\mathrm{H}^{*}$ tone of AP's. Taking into consideration previous observations made on Metropolitan and Lifou French (D'Imperio \& Michelas 2014, Torres et al. 2019), the following four hypotheses will be discussed:

H1 Complete ReSet hypothesis : In French, it could be established that a major syntactic break between an NP and a VP triggers complete reset of the $\left(\mathrm{LH}^{*}\right)$ rising tone of the AP immediately placed at this major break. Therefore, it is hypothesised that the pitch level of a $\mathrm{LH}^{*}$ rising accent of the right most peak of a complex NP is scaled at the level or close to that of the utterance initial peak (D'Imperio \& Michelas 2014). In this case, the prediction for the ratio value for the two peaks should be $=1$.

H2 Downstep BLOCKING Hypothesis : Another variation in pitch scaling that has been associated with a demarcation of a further prosodic level in French is downstep blocking of F0. Evidence was found that the F0 level of peaks within the ip was held relatively constant. More precisely, it was found that the pitch level of a $\mathrm{LH}^{*}$ rising accent immediately placed at the NP/VP break is scaled to the same level as the peak preceding it within the ip (Torres et al. 2019). In this case, we predict that the right most peak within a complex NP will be scaled to the same level as the preceding peak. This means the ratio value for peaks at the NP|VP break and the preceding AP should be $=1$.

H3 Downstep Hypothesis : According to observations in French, in a sequence of AP's [[AP][AP][AP] $]^{\text {IP }}$ where no major syntactic break or focus is marked, continuous downstep of F0 should be found throughout the whole IP. This means the pitch level of a peak at an AP boundary is downstepped relative to the peak of the preceding AP. In agreement with previous observations on Lifou French, we hypothesise that AP's at a syntactic break will not show this behaviour but rather that AP's within the ip will show downstep. This means that peaks placed within a verb or noun phrase should be clearly downstepped relative to a preceding AP. In this case, the ratio value between the peaks within the VP and NP peaks should be $<1$.

H4 Pre-Pausal PItCh ReSet : Similarly to the Metropolitan variety it is expected that a $\mathrm{H}$ tone which is accompanied by the insertion of a pause will be related to the demarcation of the IP. It is hypothesised 
that this $\mathrm{H} \%$ will be stronger than that of IP internal peaks.

\subsection{Methods}

\subsubsection{Participants}

In total 21 participants, twelve female and nine male teenage (14-20 years old) bilingual speakers of French and Drehu took part in the experiment. Participants responded to an adapted version of the sociolinguistic questionnaire BLP (Birdsong et al. 2012). They reported using both languages on a daily basis, when being raised, and that they live in a bilingual French - Drehu speaking household. Only speakers who always had New Caledonia as their main residence place and were exposed to Drehu were included in the study 6 . Two participants reported having passive knowledge of Iaai and Nengone, two Kanak languages from the neighbouring islands Ouvéa and Maré. All participants in the present experiment are enrolled at the Lycée Polyvalent des Îles and have gone through the French Metropolitan education system that has been implemented in New Caledonia.

\subsubsection{Materials}

This experiment used a set of written sentences as stimuli that were adapted to the regional context of Lifou. Elicitation materials consisted of 44 utterances (20 in the first and 24 in the second elicitation) that were separated into a two or three AP condition. In the $2 \mathrm{AP}$-condition a noun phrase that was made up of two NP's was followed by a verb phrase while in the 3 AP-condition a larger NP made up of three NP's was followed by a verb phrase. This was done in order to test whether the syntactic break between the NP and the VP would have an effect on scaling processes. The syntactic structure and corresponding intonational make up of phrases in the two and three AP conditions are here explained:

$$
\begin{array}{llll}
\text { 2-NP }[[\mathrm{NP}][\mathrm{NP}] & \left.\right|^{\text {syntactic break }} & [\mathrm{VP}]]^{\mathrm{IP}} \\
\text { 2-AP }\left[[\mathrm{AP}]^{1}[\mathrm{AP}]^{\mathrm{Fs}}\right. & \left.\right|^{\text {ip boundary? }} & [\mathrm{VP}]]^{\mathrm{IP}} \\
\text { 3-NP }[[\mathrm{NP}][\mathrm{NP}][\mathrm{NP}] & \left.\right|^{\text {syntactic break }} & [\mathrm{VP}]]^{\mathrm{IP}} \\
\text { 3-AP }\left[[\mathrm{AP}]^{1}[\mathrm{AP}]^{2}[\mathrm{AP}]^{\mathbf{F l}}\right. & \left.\right|^{\text {ip boundary? }} & [\mathrm{VP}]]^{\mathrm{IP}}
\end{array}
$$

The target tokens were AP's that in most cases contained three syllables (apart from three tokens that had 2 or 4 syllables). All target AP's always ended on a CV syllable, containing a vowel which was preceded

\footnotetext{
${ }^{6}$ One male participant who had lived for several years in Metropolitan France was excluded from the analysis.
} 
by a voiced consonant $(/ \mathrm{b} / / \mathrm{d} / / \mathrm{g} / / \mathrm{l} / / \mathrm{m} / / \mathrm{n} / / \mathrm{s} / / \mathrm{z} /)$. Materials for the first data collection were adapted from D'Imperio \& Michelas (2014) and checked for comprehensibility prior to elicitation. Examples 5 and 6 show both conditions of sentences whereby AP1 stands for first AP, AP2 for second, AP.Fs for final short (2 AP-condition), AP.Fl for final long (3 AP-condition) and Hpb for post boundary H*. All utterances used as stimuli are listed in Appendix B

(5) $\quad[\text { La mamie }]^{\text {AP.1 }}[\text { de Rémy }]^{\text {AP.Fs }}[\text { demandait }]^{\text {Hpb }}$ Bruno.

Remy's grandma asked for Bruno.

(6) $\quad[\text { La mamie }]^{\mathbf{A P . 1}}[\text { des amis }]^{\mathbf{A P . 2}}[\text { de Rémy }]^{\mathbf{A P . F 1}}{ }_{\text {demandait }}{ }^{\mathbf{H p b}}$ Bruno.

Remy's friend's grandma asked for Bruno.

\subsubsection{Procedure}

Recordings were carried out in a quiet office at Lifou's high school Lycée Polyvalent des Îles. Participants were recorded in individual sessions, at a sampling rate of 44.1 or $48 \mathrm{kH} 77$ and 16-bit depth, using a Zoom H6 Handy recorder, and a head mounted-microphone. The first author carried out the experiment, gave the necessary instructions to participants and responded to questions they had. Participants were instructed to first read aloud at a self selected normal speech rate and then after a short break read again at fast speech rate. They had time to familiarise themselves with the task and read the material before being recorded. Stimuli were visually presented on slides in a PC and the order in which the utterances appeared was randomised. For the elicitation at normal speech rate each utterance appeared alone on one slide, with no line breaks. For the recording at fast speech rate the order of the utterances was randomised again and the phrases appeared in sets of five or four on each slide.

\subsection{Data analysis}

The same procedures as in section 2.3 were followed. As exemplified in Figure 9 , the target AP's, position, and $\mathrm{H}$ tones were manually annotated (Jun \& Fougeron 2002). A hierarchical database was constructed using the EMU Speech Database Management System (Winkelmann, Harrington \& Jänsch 2017). It included tiers for the tones, syllables, words, and target AP position.

Values for the $\mathrm{H}^{*}$ tones of the target AP's were extracted in emuR (Winkelmann, Jaensch, Cassidy \& Harrington 2017, R Core Team 2017, Boersma \& Weenink 2017). To provide a psycho-acoustic analysis the frequency measured in $\mathrm{Hz}$ was converted into semitones. The formula employed for the semitone conversion

7 Deliyski et al. (2005) demonstrate F0 in recordings made at a sampling rate above $26 \mathrm{kHz}$ can be compared without showing any significant difference. 


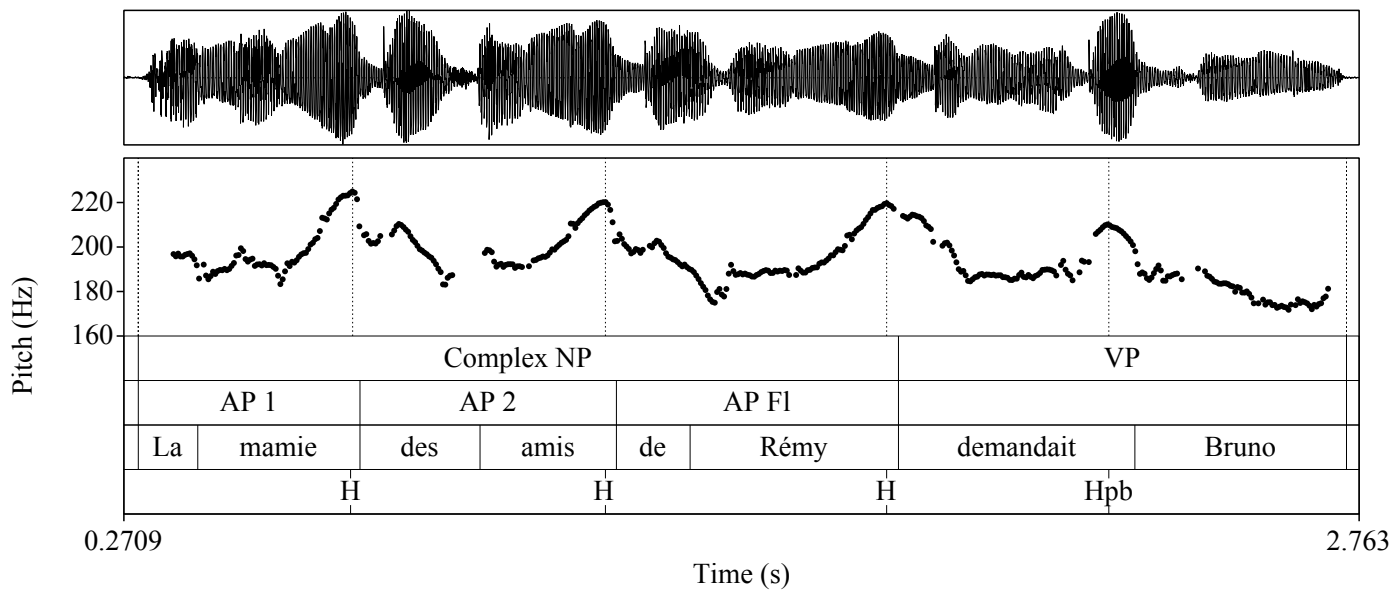

Figure 9: Waveform and F0 trace of the utterance La mamie des amis de Rémy demandait Bruno 'Remy's friends' grandma was asking for Bruno'.

employs a base- $2^{1 / 12}$ (this is the equivalent of 12 times the base-2 logarithm) (Nolan 2003). It is expected that male and female speakers will have different pitch ranges due to differences in the size of the vocal tract. However, it is expected that scaling processes will show the same trends across all speakers. To examine the relationship between peaks and the position in the utterance ratio values of $\mathrm{H}^{*}$ peak means were calculated in semitones. A ratio of one between two peaks indicates that the tonal target is not downstepped relative to each other, if one value is higher $(>1)$, then that peak is set to a higher level.

\subsubsection{Statistical analyses}

Paired Wilcoxon tests were performed to compare the speaking rate for all participants. Linear mixed effects models investigate ratio values measured for each condition and whether (i) the position of the AP, (ii) the insertion of a pause, (iii) the change in speech rate, and (iv) the sex of participants have an influence on the height of peaks. Statistical analyses were carried out in R (R Core Team 2017) with help of the packages lme4 and emmeans (Bates et al. 2015, Lenth \& Herve 2019). Automatic backward model selection was employed to arrive at a final model and obtain significance values. Additionally, estimated marginal means were obtained for factor comparisons and $p$-values were adjusted with the Tukey method. Random effects included random intercepts for speakers and words, as well as by-speaker random slopes for the effect of speech rate. 


\subsection{Results}

\subsubsection{Speaking rate}

Participants were instructed to read the stimuli at a self selected normal and fast speech rate. Since the utterances used are very similar to those in D'Imperio \& Michelas (2014) we can compare between both studies relatively well. Note that speakers in Lifou are younger (14-20 years old) than participants in the Metropolitan experiment (24-34 years old) and also that more participants were recorded in Lifou, namely 21 compared to 9 . Average number of syllables produced per second was calculated using the duration values of target AP's in ms divided by the number of syllables in the same AP. The mean syllable duration was used to arrive at an estimate of produced syllables per second. Paired Wilcoxon tests were used to examine whether participants had succeeded in increasing the speed between rates for this measure. Table 4 summarises the average number of syllables produced per second at two speech rates and provides the results for statistical analyses performed for all speakers. Similar to observations in experiment 1, participants in Lifou show a slower speaking rate. The slowest speaker (FI) produced 5.1 syllables per second and the fastest (BR) 8.2 at fast speech rate. In the study by D'Imperio \& Michelas (2014), the slowest speaker produced 7.2 and the fastest 9.8 syllables per second, at fast speech rate. Note that from 21 participants, three speakers failed to increase the number of syllables produced per target AP (AL, FI, IQ). Although most speakers managed to increase the speaking rate, in average, they did so by $14.9 \%$ while the Metropolitan speakers increased the rate by $28.4 \%$.

\subsubsection{F0 peaks}

Ratio values for relevant peak comparisons were calculated using semitone measures. Values were obtained by speaker, rate, and condition. Table 5 provides the mean values obtained for ratio comparisons in the 2 $\mathrm{AP}$ and 3 AP-conditions. The ratio between AP.Fs and AP1 measured for female and male speakers (= 0.97) shows that the AP.Fs peak is realised at a level close to the utterance initial $\mathrm{H}^{*}$ in the 2 AP-condition. A comparison between AP.Fl and AP1 $(=0.95)$ shows that also in this case the peak associated with the syntactic break is close to the utterance initial $\mathrm{H}^{*}$ in the $3 \mathrm{AP}$-condition. These ratio values show that peaks at the NP|VP syntactic break are set to a level close to that of the utterance initial peak in AP1. Although the F0 level is not set at the exact same level, these results could suggest that a moderate version of the COMPLETE RESET HYPOTHESIS could apply. However, this might not be the most suitable analysis for the observed scaling.

Another mechanism linked to the restructuring of prosodic levels in French is downstep blocking. Figure 10 shows the peak height in semitones for the right most peaks of the NP and the preceding peaks in the 2 


\begin{tabular}{lcccc}
\hline Speaker & Normal & Fast & Increment in $\%$ & $\boldsymbol{p}$ value \\
\hline Female & & & & \\
\hline AL & 5.63 & 5.57 & -1 & n.s \\
EL & 5.8 & 6.3 & 9.6 & $<.0001$ \\
EN & 6 & 7 & 15.4 & $<.0001$ \\
FI & 5.1 & 5.2 & -2.8 & n.s \\
HM & 4.8 & 6.2 & 29.6 & $<.0001$ \\
LU & 5.9 & 7.1 & 20.1 & $<.0001$ \\
OL & 5.3 & 6.9 & 31.2 & $<.0001$ \\
PI & 6.1 & 6.9 & 13.3 & $<.0001$ \\
RA & 5.9 & 6.5 & 10.8 & $<.0001$ \\
WL & 5.6 & 6.8 & 21.1 & $<.0001$ \\
WT & 5.7 & 6.3 & 11.4 & $<.0001$ \\
XE & 6.1 & 7.2 & 18.7 & $<.0001$ \\
\hline Male & & & & \\
\hline BR & 7.1 & 8.2 & 15.2 & $<.0001$ \\
DO & 5.8 & 6.9 & 19.9 & $<.0001$ \\
GU & 6 & 6.3 & 5.1 & $<.001$ \\
HE & 6.6 & 7.5 & 13.2 & $<.0001$ \\
IQ & 5.93 & 5.89 & 0.6 & n.s \\
JE & 5.9 & 7.6 & 28 & $<.0001$ \\
JO & 5.9 & 6.9 & 16.4 & $<.0001$ \\
RA & 5.8 & 7.2 & 25 & $<.0001$ \\
TH & 5.5 & 6.3 & 13 & $<.0001$
\end{tabular}

Table 4: Average syllable duration per second for normal and fast speech rate in target Accentual Phrases. The increment from normal to fast is given in percentage and paired Wilcoxon tests were used for statistical comparison providing $p$ values.

$\mathrm{AP}$ and $3 \mathrm{AP}$ condition. This graph suggests that peaks at the NP|VP break are closely scaled to preceding peaks within the same NP. To evaluate whether the peaks at the NP|VP break are scaled to the level of their respectively preceding peaks the ratio values between the right most peak of the complex-NP boundary and the preceding AP's were measured.

Table 5 shows that for this comparison, in the $2 \mathrm{AP}$ condition, the ratio is of 0.97 , while in the $3 \mathrm{AP}$ condition it is of 0.96 and 0.99 . In order to test the downstep blocking hypothesis ratio values of peaks were fitted to a linear mixed effects model $(\mathrm{N}=2800)$. The initial model had RATiO (AP.Fs/AP1, AP.Fs/Hpb, AP.Fl/AP.1, AP.Fl/AP2, AP.Fl/Hpb), RATE (normal, fast), and CONDITION (2 AP, 3 AP) as fixed factors together with speaker as random intercept and by-speaker random slopes for the effect of rate. The backward model selection retained the fixed factors RATIO and CONDITION together with the random factor and slopes. Table 6 provides the results for the Tukey corrected factor comparisons. The statistical analyses reveal that values for peaks at the syntactic break and the utterance initial $\mathrm{H}^{*}$ (AP.Fs/AP1 and AP.Fl/AP1) are not significantly different which suggests a comparable level of $\mathrm{H}^{*}$ at the NP|VP break is found for both 


\begin{tabular}{lcllc}
\hline Ratio & Prediction & Males & Females & All speakers \\
\hline 2 AP-condition & & & & \\
\hline AP.Fs/AP1 & $=1$ & 0.97 & 0.97 & 0.97 \\
AP.Fs/Hpb & $>1$ & 1.16 & 1.07 & 1.1 \\
Hpb/AP1 & $<1$ & 0.84 & 0.91 & 0.89 \\
\hline 3 AP-condition & & & & \\
\hline AP.Fl/AP1 & $=1$ & 0.94 & 0.94 & 0.96 \\
AP.Fl/AP2 & $=1$ & 0.97 & 0.97 & 0.99 \\
AP.Fl/Hpb & $>1$ & 1.1 & 1.05 & 1.06 \\
Hpb/AP1 & $<1$ & 0.85 & 0.89 & 0.90
\end{tabular}

Table 5: Calculated ratio values of right edge $\mathrm{H}^{*}$ peaks of AP's in two conditions.

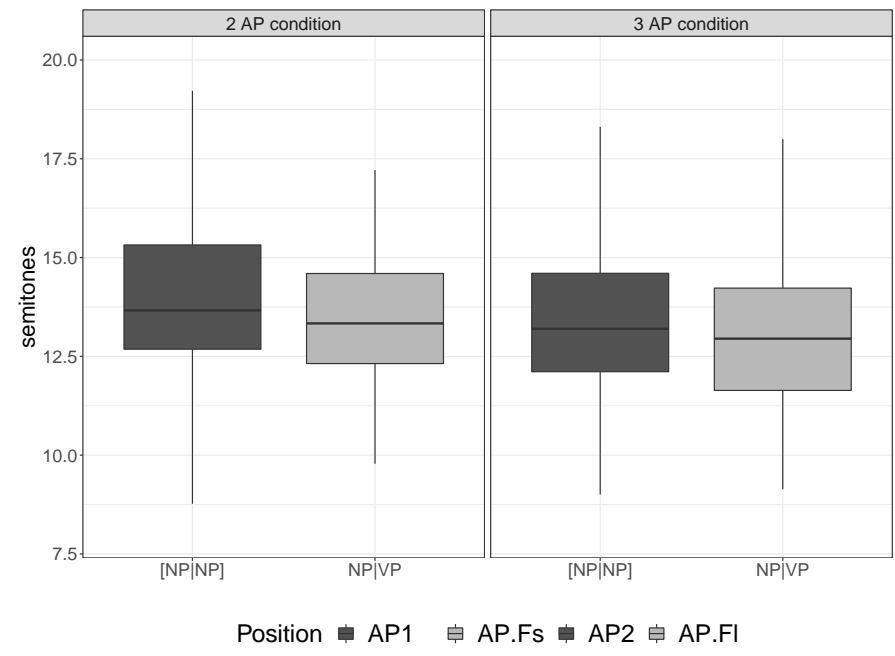

Figure 10: Peak values for $\mathrm{H}^{*}$ in semitones of female speakers for AP's occurring within the NP and at the $\mathrm{NP} \mid \mathrm{VP}$ break in two conditions. The graph includes tokens from the two elicited speech rates.

conditions. However, note that in the $3 \mathrm{AP}$ condition the difference between the ratio values of AP.Fl/AP1 and AP.Fl/AP2 is statistically significant, which does not support the downstep blocking hypothesis. This difference can be expected in case dowstep blocking does not apply across the entire NP. Instead, downstep blocking could be specifically targeting one peak, namely the NP right most one.

If the ratio values across conditions are compared for peaks at the syntactic NP|VP break and the $\mathrm{H}^{*}$ immediately preceding them (AP.Fs/AP1 and AP.Fl/AP2) we have a more robust result confirming that these peaks do not differ significantly. These results suggest that downstep blocking applies to the peak at the syntactic break (AP.Fs and AP.Fl) but not across the entire ip. Additionally, if there was a continuous downstep trend across the utterance, ratio values between AP.Fs/AP1 and AP.Fl/AP2 should have been 


\begin{tabular}{lcllc}
\hline Comparison & Estimate & St. Error & t-value & $\boldsymbol{p}$-value \\
\hline AP.Fs/AP1 and AP.Fl/AP1 & 0.04 & 0.01 & 2.67 & $=.06(\mathrm{n} . \mathrm{s})$ \\
AP.Fs/AP1 and AP.Fl/AP2 & -0.02 & 0.01 & -1.41 & $=.62(\mathrm{n} . \mathrm{s})$ \\
AP.Fl/Hpb and AP.Fs/Hpb & 0.02 & 0.02 & 0.98 & $=.87(\mathrm{n} . \mathrm{s})$ \\
$\mathrm{AP.Fl} / \mathrm{AP1}$ and AP.Fl/AP2 & -0.05 & 0.01 & -3.85 & $=.001$ \\
$\mathrm{AP.Fs} / \mathrm{Hpb}$ and AP.Fs/AP1 & -0.17 & 0.01 & -12.45 & $<.0001$ \\
$\mathrm{AP.Fl} / \mathrm{Hpb}$ and AP.Fl/AP1 & -0.19 & 0.02 & -12.12 & $<.0001$ \\
AP.Fl/Hpb and AP.Fl/AP2 & -0.13 & 0.02 & -8.57 & $<.0001$
\end{tabular}

Table 6: Results of Tukey corrected factor comparisons between ratio values.

different since AP.Fl occurs later in the utterance.
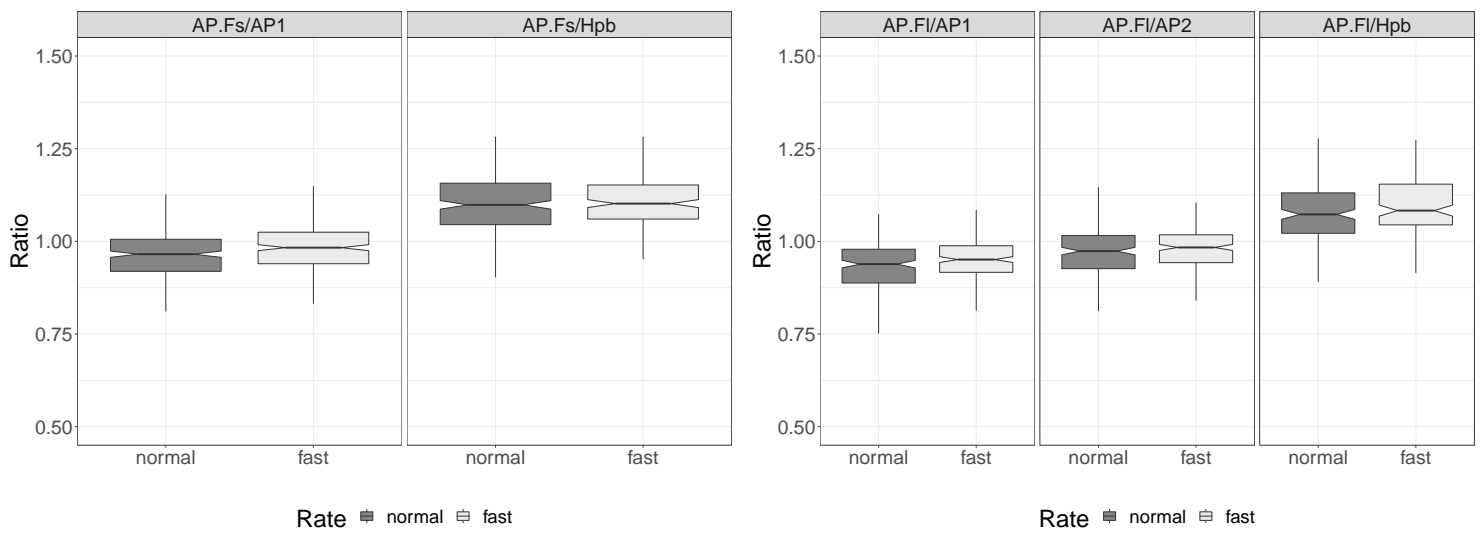

Figure 11: Ratio values of $\mathrm{H}^{*}$ peaks at two speech rates, normal and fast. To the left is the $2 \mathrm{AP}$ and to the right the $3 \mathrm{AP}$ condition

Figure 11 summarises the ratio values calculated for the $2 \mathrm{AP}$ and $3 \mathrm{AP}$ conditions at two speech rates. It shows that the ratio values between the peak at the $\mathrm{NP} \mid \mathrm{VP}$ break and the subsequent peak in the VP are higher which means that peaks in AP.Fs and AP.Fl are set to a considerably higher level than peaks in Hpb. The Tukey corrected factor comparisons show that differences of ratio values in AP.Fl/Hpb and AP.Fs/Hpb are not statistically significant. Again, if there was a continuous downstep trend across utterances, we would expect ratio values between $\mathrm{AP} . \mathrm{Fl} / \mathrm{Hpb}$ and $\mathrm{AP} . \mathrm{Fs} / \mathrm{Hpb}$ to be significantly different since Hpb occurs later in the 3-AP condition. Taken together results from statistical analyses suggest that peaks located at the NP|VP break are scaled to the level of the immediately preceding peak in the ip and are affected by downstep blocking whereas peaks following thereafter $(\mathrm{Hpb})$ show downstep.

Figure 12 shows a comparison between peaks of AP's at the major syntactic break in the $2 \mathrm{AP}$ and 3 AP conditions. Downstep was predicted across peaks of subsequent AP's in cases where no ip boundary marking would be triggered through the NP|VP break. 
To examine whether there is downstep after the syntactic break the ratio values were measured between AP.Fs and the peak in the following AP namely Hpb. Here, the mean ratio value is of 1.1. A similar result is obtained between AP.Fl and the peak in the following peak Hpb, which is 1.06, in this case. To statistically investigate the $\mathrm{H}^{*}$ of AP's, a linear mixed effects model was used, it had POsition (AP1, AP.Fs, Hpb and AP1, AP2, AP.Fl, Hpb), SPEECH RATE (normal, fast), SEX (male, female), CONDITION (2 AP, 3 AP) together with speaker and token word as random factors and by-speaker random slopes for the effect of speech rate $(\mathrm{N}=3373)$. This model only included peaks which were not preceded by a pause. The backward model selection retained the fixed factors POSITION, and SEX as well as the random effects.

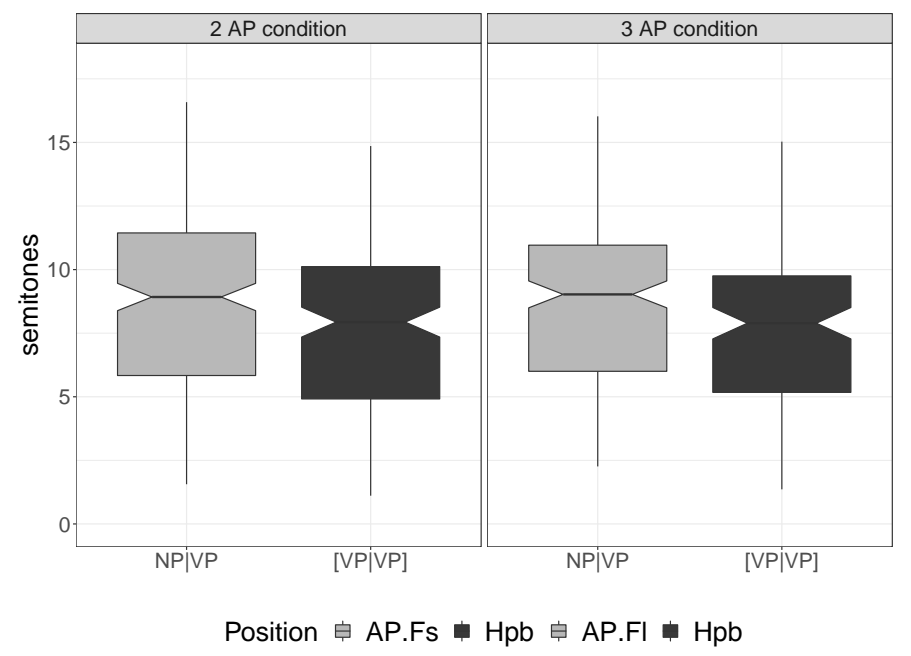

Figure 12: Mean peak values for $\mathrm{H}^{*}$ in semitones of male speakers in two subsequent AP's within an IP. The first break shows the peaks in the $2 \mathrm{AP}$-condition while the second break shows peaks in the $3 \mathrm{AP}$-condition. The graph includes tokens from the two elicited speech rates.

Results of the Tukey corrected factor comparisons for the 2 AP and 3 AP-condition are summarised in Table 7. The statistically significant difference between peaks at and after the NP|VP break indicate the DownsteP HYPOTHESIS applies to peaks realised after the complex-NP. Further evidence comes from the results shown in Table 6 which indicate that in the $2 \mathrm{AP}$ condition the ratio values between AP.Fs/Hpb and AP.Fs/AP1 are significantly different. Similarly, a comparison between the peaks in the 3 AP condition and ratio values between $\mathrm{AP} . \mathrm{Fl} / \mathrm{Hpb}$ and $\mathrm{AP} . \mathrm{Fl} / \mathrm{AP} 1$ as well as between $\mathrm{AP} . \mathrm{Fl} / \mathrm{Hpb}$ and $\mathrm{AP} . \mathrm{Fl} / \mathrm{AP} 2$ are statistically significant. Taken together, the results discussed for Tables 7 and 6 provide supporting evidence for the DownsteP HYPOTHESIS which was predicted to apply on peaks following after the syntactic break $(\mathrm{Hpb})$ and which occur within the phrase (AP2 relative to AP1 in the $3 \mathrm{AP}$ condition).

Finally, we were interested in investigating whether the insertion of a pause, the speaking rate, and the sex of the speakers had an effect on peak height. A third linear mixed effects model was employed to 


\begin{tabular}{lclll}
\hline Comparison & Estimate & St. Error & t-value & $\boldsymbol{p}$-value \\
\hline 2 AP-condition & & & & \\
\hline AP.Fs and Hpb & 0.94 & 0.16 & 5.97 & $<.0001$ \\
Hpb and AP1 & 1.39 & 0.16 & 8.76 & $<.0001$ \\
\hline 3 AP-condition & & & & \\
\hline AP.Fl and Hpb & 0.64 & 0.16 & 3.96 & $=.008$ \\
Hpb and AP1 & 1.51 & 0.16 & 9.21 & $<.0001$
\end{tabular}

Table 7: Results of Tukey corrected factor comparisons.

examine the $\mathrm{H}^{*}$ peaks in the corpus, this time including pre-pausal items. The model had PAUSE (yes, no), Position (AP1, AP.Fs, Hpb and AP1, AP2, AP.Fl, Hpb), sPEECH RATE (normal, fast), sex (male, female), plus speaker and token word as random factors and by-speaker random slopes for the effect of speech rate $(\mathrm{N}=3556)$. Table 8 summarises the results for the three investigated factors. Although of small magnitude, results show that the insertion of a pause after AP's, causes the tones to be significantly higher than other peaks. The raising of F0 in this particular case can be associated with the demarcation of a higher prosodic level, namely the IP. Further, we could not establish a signifiant difference of pitch height across speech rates which indicates that speakers seek to reach the same tonal height despite the adjustment. Finally, as it is to expect, we find a significant difference between the peaks of female and male speakers, with males having a lower range. As predicted and previously discussed, the trends in scaling processes are stable for male and female speakers despite differences in F0 range.

\begin{tabular}{lclll}
\hline Effect & Estimate & St. Error & t-value & $\boldsymbol{p}$-value \\
\hline Pause (with) & 0.48 & 0.08 & 5.65 & $<.0001$ \\
Rate (fast) & -0.15 & 0.11 & -1.42 & $=.17(\mathrm{n} . \mathrm{s})$ \\
Sex (male) & -5.71 & 1.18 & -4.84 & $<.0001$
\end{tabular}

Table 8: Results of linear mixed effect models.

\subsection{Summary}

Experiment II aimed at investigating the right boundary of AP's to evaluate whether there are phonetic cues distinguishing between three different prosodic levels. First, the speaking rate in syllables per second was calculated to test whether participants significantly increased the rate. Measurements for speaking rate suggest that Lifou French speakers have a slower rate than Metropolitan speakers which is in agreement with our observations in experiment 1. Based on previous observations, it was hypothesised that prosodic phrasing in Lifou French would differ in its phonetic realisation in comparison to the Metropolitan variety. 
It could be established that downstep blocking plays a role in the demarcation of an AP right boundary found at major syntactic break between a Noun Phrase and a Verb Phrase. Moreover, downstep blocking was found to affect the peak at the NP|VP break and not all peaks in the noun phrase. This indicates that downstep blocking applies to the AP associated with the ip-boundary. Additional evidence supporting pitch scaling effects is found at the right boundary of AP's that occur within the noun or verb phrase. In these cases it was found that there is a small degree of downstep and that peaks were lowered. This confirms that similar to what had previously been found for another French variety, the insertion of an ip-boundary is associated with a H- tone which demarcates this prosodic level. However, we do not find that the peak at the ip boundary is reset relative to the level of the ip-initial peak but rather that continuous downstep is blocked. Moreover, we were interested in investigating whether pre-pausal peaks would be influenced by the insertion of a pause and found evidence that the peak height is indeed significantly affected. This shows that the insertion of a pause causes the $\mathrm{H}^{*}$ to be higher which can be associated with the demarcation of a higher prosodic level, namely the IP.

\section{Discussion and Conclusion}

Results from two experiments showed that Lifou French shares basic elements with the intonational phonology of Metropolitan French and that these elements are subject to fine grained phonetic variation regarding the implementation of rise time, speaking rate, and scaling of F0. Basic elements of the French intonational phonology refers here to the tonal structure of the AP, the tonal targets it includes, and how they are aligned in relation to segmental landmarks. The AP is the lowest tonally marked constituent in Lifou French as well as in Metropolitan French and can be canonically described with the notation /LHiLH*/. No striking differences were found in the tune-to-text alignment of the initial and late rise which for Lifou French is similarly variable as it is for the Metropolitan variety. Although a slight preference to realise the final rise on the last syllable of the AP was observed for Lifou French, there was still some degree of variability in the data. The examination of tonal alignment of Metropolitan French led to propose the notion of anchorage region (Welby \& Lœvenbruck 2006), a concept that holds for the here studied variety and is preferable to predictions based on the strict segmental anchoring hypothesis for the study of French varieties. As described by Welby (2006), it could be established that $\mathrm{L}_{1}$ in the initial rise and the $\mathrm{H}^{*}$ tone of the late rise are tied to a region of the AP and not to one specific segment. More precisely, the $\mathrm{L}_{1}$ is an edge seeking tone that is most frequently realised at the boundary of a function word and a following content word of the AP. The $\mathrm{H}^{*}$ tone is consistently aligned with the last full syllable of the AP and does not cross over to a subsequent AP, in contrast to what has been noted for the Metropolitan variety. A similar stability of these tones, in relation 
to syllabic landmarks, had been noted for Vaudois French (Sertling-Miller 2007). The here presented results as well as the study on Vaudois French support the idea that French intonational phonology and its tonal primitives are stable across different varieties. We could establish that the best predictor of the variable tones $\mathrm{Hi}$ and $\mathrm{L}_{2}$ is the duration of the $\mathrm{AP}$ or content word which suggests that these tones might be inserted for rhythmic reasons but are not further tied to segmental landmarks.

French speakers seem aware of dialectal variation and often refer to noticeable "melodic" differences which we should address. Similar to previous observations on Swiss French (Schwab \& Avanzi 2015), results from experiment 1 suggest that Lifou French speakers show a slower speaking rate than Metropolitan speakers and this observation was further confirmed in experiment 2. Considering that French pitch accents differ from Germanic pitch accents in that they have different prosodic functions and don't show the same variability in their make up but remain constant, it is conceivable that together with differences in tempo gradient phonetic variation leads to the perceived divergent intonation.

The aim of Experiment 2 was to investigate the right boundary marking of prosodic constituents and evaluate how they relate to the French prosodic hierarchy. It could be established that the insertion of a pause causes pre-pausal peaks to be higher which can be associated with the demarcation of the IP. Our results also demonstrate that there is a restructuring of peaks associated with the intermediate phrase level. Although evidence is found for this prosodic level, intonationally the ip in Lifou French is marked in a different way than in the Metropolitan variety. First, there is less variation between peaks in Lifou French and secondly, we do not observe complete pitch reset. Instead, the demarcation of the ip is realised through downstep blocking at the ip boundary which hinders the otherwise expected recursive downstep. Further evidence is found in the speech stream following after the ip-boundary which is set to a lower register and clearly dowstepped relative to the preceding pitch level. Moreover, AP's within the same noun or verb phrase which do not coincide with the ip boundary are affected by downstep. In terms of variability, the observed scaling could signal a different rhythmicity to Metropolitan French speakers who could expect more variation in pitch. This is because in the Metropolitan variety the ip boundary is marked through reset and this involves a higher pitch level of the peak at the ip-boundary when compared to its preceding peak. Since in Lifou French these two peaks are scaled to the same level, this could be perceived as a difference in the scaling of F0 then associated with a different rhythmicity. Similar to Metropolitan speakers from southern France, we found evidence that pitch height of peaks is stable across speech rates (D'Imperio \& Michelas 2014) which was not observed for speakers from Paris, who produced lower F0 peaks at fast speech rate (Fougeron \& Jun 1998).

Our results confirm an initial hypothesis predicting regional variation in relation to prosodic phrasing. Moreover, we find evidence that suggests Lifou French speakers show a slower tempo than Metropolitan 
speakers. Arguably, the attested scaling of F0 and tempo described for Lifou French contribute together and mark the characteristic intonation of this variety. This study adds to our knowledge on dialectal variation and shows that also for a language like French, intonation represents a regional marker. Since the bitonal LH* French pitch accent does not vary in its composition as a tune, only an acoustic investigation of subsequent peaks within the Intonation Phrase has revealed that phonetic realisation is the source of moderate variation. It would be of interest to test perceptually how strongly Lifou and Metropolitan French speakers perceive the here described ip-boundary. This study is part of a larger project which investigates prosody in Lifou French and Drehu. Findings on the intonational structure of Drehu show that there is phrasal prominence marking which resembles that of French intonational phonology. Evidence was found for a low tone demarcating the left edge while a high tone was found at the right edge (Torres \& Fletcher 2020). There are two possible scenarios regarding these similarities, first, the rather recent but strong influence of French could be having an effect on Drehu intonational phonology, leading to convergence. Second, there is reason to assume the original impressionistic description of lexical stress in Drehu was not correct. Further investigation is required to validate either hypothesis. It would be of interest to examine more in detail prosodic realisations of the bilinguals and test, for example, whether there are differences between the two languages in register level or in the perception of prominence. 


\section{Appendices}

\section{A Experiment 1 - Materials}

The materials for this experiment are taken from Welby (2003). Target tokens are marked in bold.

1. (a) Le moulin va être apprecié par Hélène.

(b) Et le moulin va être apprecié par Hélène.

(c) Le beau paysage, le moulin et la cathédrale vont être appreciés par Hélène.

(d) Le beau paysage et le moulin vont être appreciés par Hélène.

'The beautiful countryside, the mill, and the cathedral are going to be appreciated by Hélène.'

2. (a) Le minime sera captivé par le match.

(b) Et le minime sera captivé par le match.

(c) Les entraineurs, le minime et les spectateurs seront captivés par le match.

(d) Les entraineurs et le minime seront captivés par le match.

'The coach, the young player, and the spectators will be captivated by the match.'

3. (a) La mignonne était observée par l'espion.

(b) Et la mignonne était observée par l'espion.

(c) La courageuse, la mignonne et le malveillant étaient observés par l'espion.

(d) La courageuse et la mignonne étaient observées par l'espion.

'The courageous woman and the cute woman were watched by the spy.'

4. (a) La lumière était désirée par Aimée.

(b) Et la lumière était désirée par Aimée.

(c) La solitude, la lumière et la propreté étaient désirées par Aimée.

(d) La solitude et la lumière étaient désirées par Aimée.

'Solitude, light, and cleanliness were desired by Aimée.'

5. (a) La mouillure est un vrai problème au sous-sol.

(b) Et la mouillure est un vrai problème au sous-sol.

(c) La moisissure, la mouillure et l'humidité sont de vrais problèmes au sous-sol. 
(d) La moisissure et la mouillure sont de vrais problèmes au sous-sol.

'Mildew, dampness, and humidity are real problems in the basement.'

6. (a) Le magnanime peut être trouvé dans le café.

(b) Et le magnanime peut être trouvé dans le café.

(c) La courageuse, le magnanime et le valeureux peuvent être trouvés dans le café.

(d) La courageuse et le magnanime peuvent être trouvés dans le café.

'The courageous woman, the magnanimous man, and the brave man can be found in the cafe.'

7. (a) Le mélomane s'était disputé avec eux.

(b) Et le mélomane s'était disputé avec eux.

(c) Le randonneur, le mélomane et la forestière s'étaient disputés avec eux.

(d) Le randonneur et le mélomane s'étaient disputés avec eux.

'The hiker and the music lover had argued with them.'

8. (a) Le minimum sera calculé par Manon.

(b) Et le minimum sera calculé par Manon.

(c) Le maximum, le minimum et les écart-types seront calculés par Manon.

(d) Le maximum et le minimum seront calculés par Manon.

'The maximum, the minimum, and the standard deviations will be calculated by Manon.'

9. (a) La mélanine était etudiée à la fac.

(b) Et la mélanine était etudiée à la fac.

(c) Le mélanome, la mélanine et le collagène étaient etudiés à la fac.

(d) Le mélanome et la mélanine étaient etudiés à la fac.

'Melanomas and melanine were studied at college.'

10. (a) La limonade a été versée par Anna.

(b) Et la limonade a été versée par Anna.

(c) La grenadine, la limonade et l'Orangina ont été versées par Anna.

(d) La grenadine et la limonade ont été versées par Anna.

'The grenadine, the lemonade and the Orangina were poured by Anna.' 
11. (a) La lanoline a été vendue à la ferme.

(b) Et la lanoline a été vendue à la ferme.

(c) Le basilic, la lanoline et les aubergines ont été vendus à la ferme.

(d) Le basilic et la lanoline ont été vendus à la ferme.

'The basil, the lanolin, and the eggplants were sold at the farm.'

12. (a) Les homonymes sont utilisés par le poète.

(b) Et les homonymes sont utilisés par le poète.

(c) Les enchaînements, les homonymes et les métaphores sont utilisés par le poète.

(d) Les enchaînements et les homonymes sont utilisés par le poète.

'Enchaînements, homonyms and metaphors are used by the poet.'

13. (a) Le linoléum sera installé mercredi.

(b) Et le linoléum sera installé mercredi.

(c) L'aluminium, le linoléum et le formica seront installés mercredi.

(d) L'aluminium et le linoléum seront installés mercredi.

'The aluminum, the linoleum, and the formica will be installed Wednesday.'

14. (a) Le méli-mélo va déconcentrer Mélanie.

(b) Et le méli-mélo va déconcentrer Mélanie.

(c) L'incohérence, le méli-mélo et la confusion vont déconcentrer Mélanie.

(d) L'incohérence et le méli-mélo vont déconcentrer Mélanie.

'The inconsistency, the disorder, and the disarray are going to distract Mélanie.'

15. (a) La monomanie doit être evitée par les empereurs.

(b) Et la monomanie doit être evitée par les empereurs.

(c) La malveillance, la monomanie et le fanatisme doivent être evités par les empereurs.

(d) La malveillance et la monomanie doivent être evitées par les empereurs.

'Malevolence, monomania, and fanatism must be avoided by emperors.'

16. (a) La mammalogie va être importante pour Jérôme.

(b) Et la mammalogie va être importante pour Jérôme. 
(c) L'agriculture, la mammalogie et la fauconerie vont être importantes pour Jérôme.

(d) L'agriculture et la mammalogie vont être importantes pour Jérôme.

'Agriculture, mammalogy, and falconry are going to be important for Jerome.'

17. (a) Les Himalayens se sont rencontrés l'autre semaine.

(b) Et les Himalayens se sont rencontrés l'autre semaine.

(c) Les photographes, les Himalayens et les Grenoblois se sont rencontrés l'autre semaine.

(d) Les photographes et les Himalayens se sont rencontrés l'autre semaine.

'The photographers, the Himalayans, and the Grenoblois met one another the other week.'

\section{B Experiment 2 - Materials}

The materials used in this experiment were taken from D'Imperio \& Michelas (2014) and modified by the first author. Phrases containing words that potentially did not suit the cultural context or seemed rather infrequent (for example "sauna") were discarded and only those that were considered to better suit the cultural context and could be understood by young participants were kept.

1. (a) La mamie de Rémy demandait Bruno.

(b) La mamie des amis de Rémy demandait Bruno.

'Rémy's friends' granny asked for Bruno.'

2. (a) Au resto de Bruno je mange toujours la purée de céleri.

(b) Au resto de Bruno à Ouémo je mange toujours la purée de céleri.

'In Bruno's restaurant in Ouémo I always eat celery puree.'

3. (a) La mairie de Paris se trouve en face de l'académie.

(b) Le parvis de la mairie de Paris se trouve en face de l'académie.

'The forecourt of the town hall of Paris is in front of the academy.'

4. (a) Le tabac de Cuba tu le trouveras en bas.

(b) Le prix de tabac de Cuba est énormément bas.

'The price of Cuban tobacco is dramatically low.'

5. (a) Les parents de Laurent devaient présenter leur dossier au gérant. 
(b) Le garant des parents de Laurent devait presenter leur dossier au gérant.

'The warrantor of Laurent's parents should present their file to the manager.'

6. (a) Le roman de Clément se lit facilement.

(b) Le roman de la maman de Clément se lit facilement.

'The novel of Clément's mother is easy to read.'

7. (a) Les colis d'Elodie devraient arriver ce lundi.

(b) Les colis alourdis d'Elodie devraient arriver ce lundi.

'The heavy packages of Élodie should arrive this Monday.'

8. (a) Les soirées du curé devenaient de plus en plus adorées.

(b) Les soirées du curé de Poiret devenaient de plus en plus adorées.

'The receptions by the priest from Poiret became increasingly popular.'

9. (a) La villa de Ferdinand demandait des travaux permanents.

(b) La villa de Ferdinand en Iran demandait des travaux permanents.

'Ferdinand's villa in Iran required permanent work.'

10. (a) La maison de Manon a été vendue à Raymond.

(b) La maison de Manon à Beaumont a été vendue à Raymond.

'Manon's house in Beaumont was sold to Raymond.'

The materials used in the second data collection of Experiment 2 were developed by the first author. Materials include objects (bougna - traditional dish from Lifou) and names of places found in Lifou (Drueulou) or other Places of New Caledonia (Hanawa and Ouémo).

1. (a) Le loulou de Manon demeura au Mali.

(b) Le bijou du loulou de Margot se trouva au Mali.

'The jewel of Margot's little one was in Mali.'

2. (a) Le gourou de Laura demanda son bougna.

(b) Le gourou de Manon à Drueulou demanda son bougna. 'Manon's guru in Drueulou asked for his bougna.' 
3. (a) La nana au boulot arriva en vélo.

(b) La nana au boulot de Manou arriva en vélo.

'The girl at Manou's work arrived on a bicycle.'

4. (a) Le jumeau de Malou demanda son doudou.

(b) Le jumeau du loulou de Laura demanda son doudou.

'The twin of Laura's little one asked for his teddy.'

5. (a) La journée de Manon termina au Mali.

(b) La journée de René et Manon termina au Mali.

'René and Manon's day ended in Mali.'

6. (a) Le minou de Margot demeurait à Ouémo.

(b) Le minou du boulot de René demeurait à Ouémo.

'The kitty of René's work stayed in Ouémo.'

7. (a) La villa de Manou se trouvait à Ouémo.

(b) La villa de Raymond et Malou se trouvait à Riga.

'Raymond and Malou's villa was in Riga.'

8. (a) La maison d'Alizée se trouvait à Paris.

(b) La maison du loulou de Margot se trouvait à Ouémo.

'The house of Margot's little one was in Ouémo.'

9. (a) Les aînés de Drueulou visitaient Hanawa.

(b) Les aînés de Laura et Manon visitaiant Hanawa.

'The eldests from Drueulou visited Hanawa.'

10. (a) Le vélo de René se trouvait à Drueulou.

(b) Le vélo du loulou d'Héléna se trouvait à Drueulou.

'The bicycle of Héléna's little one was in Drueulou.

11. (a) Le patron d'Héléna demanda son loulou.

(b) Le patron de René et Alizée demanda son loulou. 
'René and Alizée's boss asked for his little one.'

12. (a) Le doudou de René se trouvait à Riga.

(b) Le doudou de Laura et René se trouvait à Paris.

'Laura and René's teddy was in Paris.' 


\section{References}

Barnèche, S. (2005), Gens de Nouméa, gens des îles, gens d'ailleurs...: langues et identités en NouvelleCalédonie, Editions L'Harmattan.

Bates, D., Mächler, M., Bolker, B. \& Walker, S. (2015), 'Fitting Linear Mixed-Effects Models Using lme4', Journal of Statistical Software 67(1), 1-48.

Birdsong, D., Gertken, L. M. \& Amengual, M. (2012), 'Bilingual language profile: An easy-to-use instrument to assess bilingualism', COERLL, University of Texas at Austin .

Boersma, P. (2007), 'Some listener-oriented accounts of h-aspiré in French', Lingua 117(12), 1989-2054.

Boersma, P. \& Weenink, D. (2017), 'Praat: doing phonetics by computer (version 6.0.26)[computer program]. Retrieved November 2, 2017'.

Colombel-Teuira, C., Fillol, V., Geneix-Rabault, S. \& Vandeputte, L. (2017), 'Les langues dans la ville de Nouméa: sociolinguistique urbaine et interdisciplinarité', Socles .

Crowley, T., Lynch, J. \& Ross, M. (2013), The Oceanic languages, Routledge.

Delais-Roussarie, E., Brechtje, P., Avanzi, M., Buthke, C., Di Cristo, A., Feldhausen, I., Jun, S.-A., Martin, P., Meisenburg, T., Rialland, A., Sichel-Bazin, R. \& Yoo, H. (2015), Intonational phonology of French: Developing a ToBI system for French, in 'Intonation in Romance', Oxford University Press, chapter 3, pp. 63-139.

Deliyski, D. D., Shaw, H. S. \& Evans, M. K. (2005), 'Influence of sampling rate on accuracy and reliability of acoustic voice analysis', Logopedics Phoniatrics Vocology 30(2), 55-62.

Di Cristo, A. (1998), Intonation in French, Cambridge University Press, pp. 195-218.

D'Imperio, M. \& Michelas, A. (2010), Embedded register levels and prosodic phrasing in French, in 'Speech Prosody', p. 4.

D'Imperio, M. \& Michelas, A. (2014), 'Pitch scaling and the internal structuring of the Intonation Phrase in French', Phonology 31(1), 95-122.

Dotte, A.-L., Geneix-Rabault, S. \& Vandeputte, L. (2017), 'Nouméa at the Crossroad of New Caledonian Multilingualism', Amerasia Journal 43(1).

Ehrhart, S. (2016), 'Entre français calédonien et langue kanak: quelle place pour le tayo? Une approche écolinguistique', Langages (3), 37-48. 
Fillol, V. (2016), 'Les (auto) biographies langagières comme outil de lecture de la situation postcoloniale en Nouvelle-Calédonie et comme outil d'empowerment dans une démarche sociodidactique', Contextes et Didactiques .

Fougeron, C. \& Jun, S.-A. (1998), 'Rate effects on French intonation: Prosodic organization and phonetic realization', Journal of Phonetics 26(1), 45-69.

Gertken, L. M., Amengual, M. \& Birdsong, D. (2014), 'Assessing language dominance with the bilingual language profile', Measuring L2 proficiency: Perspectives from SLA pp. 208-225.

Harrington, J. (2010), Acoustic phonetics, in J. H. William, J. Laver \& F. E. Gibbon, eds, 'The handbook of phonetic sciences', Vol. 2, Wiley-Blackwell, pp. 81-129.

Hollyman, J. (1964), 'L'ancien pidgin français parlé en Nouvelle-Calédonie', Journal de la Société des Océanistes 20(20), 57-64.

Hollyman, J. (1971), French in the Pacific, in T. Seboek, ed., 'Linguistics in Oceania', Mouton, pp. 903-937.

Hollyman, J. (1979), 'Le français en Nouvelle-Calédonie', A. Valdman (éd.), Le Français hors de France, Paris: Honoré Champion pp. 621-629.

Hualde, J. I. \& Prieto, P. (2015), Intonational variation in Spanish: European and American varieties, Oxford University Press Oxford, pp. 9-62.

Jun, S.-A. (2014), Prosodic typology: by prominence type, word prosody, and macro-rhythm, Oxford University Press, pp. 520-540.

Jun, S.-A. \& Fougeron, C. (2000), 'A phonological model of French intonation', Intonation: Analysis, modeling and technology pp. 209-242.

Jun, S.-A. \& Fougeron, C. (2002), 'Realizations of accentual phrase in French intonation', Probus 14(1), 147172.

Jun, S.-A. \& Jiang, X. (2018), 'Differences in prosodic phrasing in marking syntax vs. focus: Data from Yanbian Korean', The Linguistic Review .

Kaisse, E. M. (2001), 'The long fall', Features and interfaces in Romance: Essays in honor of Heles Contreras 222, 147.

Kihm, A. (1995), 'Tayo, the strange bird from New Caledonia: determiners and tense-aspect in Tayo and their implications for creolization theories', Journal of Pidgin and Creole languages 10(2), 225-252. 
Kisler, T., Reichel, U. \& Schiel, F. (2017), 'Multilingual processing of speech via web services', Computer Speech \& Language 45, 326-347.

Labov, W. (1986), The social stratification of (r) in New York City department stores, in 'Dialect and language variation', Elsevier, pp. 304-329.

Lenormand, M.-H. (1954), 'La phonologie du mot en lifou (îles loyalty)', Journal de la Société des Océanistes 10(10), 91-109.

Lenth, R. \& Herve, M. (2019), 'Emmeans: Estimated marginal means, aka least-square means. R package version 1.1. 2'.

Lewis, E. (2015), Acoustic phonetic properties of mid vowels in New Caledonian French, in 'Proceedings of 18th International Congress of Phonetic Sciences'.

Lewis, E. (2019), New Caledonian french nasal vowels: an acoustic study, in 'Proceedings of 19th International Congress of Phonetic Sciences'.

Mendoza-Denton, N. (2014), Homegirls: Language and cultural practice among Latina youth gangs, John Wiley \& Sons.

Mertens, P. (1987), L'intonation du français. De la description linguistique à la reconnaissance automatique, $\mathrm{PhD}$ thesis.

Michelas, A. \& D’Imperio, M. (2012), 'When syntax meets prosody: Tonal and duration variability in French Accentual Phrases', Journal of Phonetics 40(6), 816-829.

Nolan, F. (2003), Intonational equivalence: an experimental evaluation of pitch scales, in 'Proceedings of the 15th International Congress of Phonetic Sciences, Barcelona', Vol. 39.

Pasdeloup, V. (1992), 'A prosodic model for French text-to-speech synthesis: A psycholinguistic approach', Talking Machines. Theories, Models and Designs pp. 335-348.

Pauleau, C. (1988), Etude phonétique contrastive du français néo-calédonien et du français standard, Master's thesis.

Post, B. M. B. (2000), Tonal and phrasal structures in French intonation, Vol. 34, Thesus The Hague.

R Core Team (2017), R: A Language and Environment for Statistical Computing, R Foundation for Statistical Computing, Vienna, Austria.

URL: https://www.R-project.org/ 
Recensement général de la population (2014).

Rossi, M. (1985), 'L'intonation et l'organisation de l'énoncé', Phonetica 42(2-3), 135-153.

Schwab, S. \& Avanzi, M. (2015), 'Regional variation and articulation rate in French', Journal of Phonetics 48, 96-105.

Sertling-Miller, J. (2007), Swiss French prosody: intonation, rate, and speaking style in the Vaud canton, $\mathrm{PhD}$ thesis, University of Illinois at Urbana-Champaign.

Torres, C. \& Fletcher, J. (2020), 'The alignment of F0 tonal targets under changes in speech rate in Drehu', Journal of the Acoustical Society of America 147(4), 2947-2958.

Torres, C., Fletcher, J. \& Wigglesworth, G. (2018a), Acoustic correlates of the French Accentual Phrase in Lifou (New Caledonia), in 'Proc. 9th International Conference on Speech Prosody 2018', pp. 636-640.

Torres, C., Fletcher, J. \& Wigglesworth, G. (2018b), Investigating word prominence in Drehu, in 'Proc. 17th Speech Science and Technoloy conference'.

Torres, C., Fletcher, J. \& Wigglesworth, G. (2019), Phrasing and Constituent Boundaries in Lifou French, in 'Proceedings of the 19th International Congress of Phonetic Sciences'.

Tryon, D. T. (1963), Le français parlé aux Iles Loyauté, Master's thesis, University of Canterbury.

Tryon, D. T. (1968), Dehu grammar, Australian National University.

Vaissière, J. (1991), Rhythm, accentuation and final lengthening in French, in 'Music, language, speech and brain', Springer, pp. 108-120.

Vernaudon, J. (2015), 'Linguistic Ideologies: Teaching Oceanic Languages in French Polynesia and New Caledonia', The Contemporary Pacific 27(2), 433-462.

Welby, P. (2003), The slaying of Lady Mondegreen, being a study of French tonal association and alignment and their role in speech segmentation, $\mathrm{PhD}$ thesis, The Ohio State University.

Welby, P. (2006), 'French intonational structure: Evidence from tonal alignment', Journal of Phonetics 34(3), 343-371.

Welby, P. \& Lœenenbruck, H. (2006), 'Anchored down in anchorage: Syllable structure and segmental anchoring in French', Italian Journal of Linguistics/Rivista di linguistica 18, 74-124. 
Winkelmann, R., Harrington, J. \& Jänsch, K. (2017), 'Emu-sdms: Advanced speech database management and analysis in r', Computer Speech \& Language 45, 392-410.

Winkelmann, R., Jaensch, K., Cassidy, S. \& Harrington, J. (2017), emuR: Main Package of the EMU Speech Database Management System. R package version 0.2.3. 


\section{University Library}

\section{- M M I E E R VA A gateway to Melbourne's research publications}

Minerva Access is the Institutional Repository of The University of Melbourne

Author/s:

Torres, C;Fletcher, J;Wigglesworth, G

Title:

Fundamental Frequency and Regional Variation in Lifou French

Date:

2020-09-17

Citation:

Torres, C., Fletcher, J. \& Wigglesworth, G. (2020). Fundamental Frequency and Regional Variation in Lifou French. LANGUAGE AND SPEECH, 65 (4), pp.889-922. https:// doi.org/10.1177/0023830920952497.

Persistent Link:

http://hdl.handle.net/11343/258685 